\title{
La historia de los intelectuales durante el franquismo: un ensayo bibliográfico
}

L'histoire des intellectuels durant le franquisme: un essai bibliographique

The history of the intellectuals during the Francoism: a bibliographical essay

\section{Francisco Morente}

\section{OpenEdition}

\section{Journals}

Edición electrónica

URL: http://journals.openedition.org/bhce/583

DOI: 10.4000/bhce.583

ISSN: 1968-3723

Editor

Presses Universitaires de Provence

Edición impresa

Fecha de publicación: 1 diciembre 2016

Paginación: 163-194

ISSN: 0987-4135

Referencia electrónica

Francisco Morente, "La historia de los intelectuales durante el franquismo: un ensayo bibliográfico », Bulletin d'Histoire Contemporaine de l'Espagne [En línea], 50 | 2016, Publicado el 09 octubre 2018, consultado el 10 diciembre 2020. URL : http://journals.openedition.org/bhce/583 ; DOI : https:// doi.org/10.4000/bhce.583 


\title{
La historia de los intelectuales durante el franquismo: un ensayo bibliográfico*
}

\author{
Francisco MORENTE
}

Universitat Autònoma de Barcelona

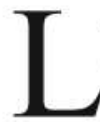
a historia de los intelectuales ha ido afianzándose en las últimas décadas como un territorio especialmente fructífero de la historia cultural en su cruce con la historia del pensamiento. Como inmediatamente se explicará, los límites de esos tres campos de trabajo no son siempre claros y los solapamientos entre unos y otros son no sólo frecuentes sino inevitables. Pero ello, lejos de ser un inconveniente, representa, en mi opinión, una inmejorable oportunidad para escapar de las visiones más tradicionales de la historia de las ideas (y de quienes las crean) e incorporar las herramientas de trabajo y las perspectivas analíticas, en su casi interminable variedad, con que la moderna historia cultural ha enriquecido el arsenal epistemológico y metodológico de los historiadores ${ }^{1}$. Tras unas breves consideraciones sobre la historia cultural y la historia de las ideas que permitan enmarcar adecuadamente el tema, este trabajo se plantea no tanto formular un ensayo interpretativo sobre los intelectuales durante el franquismo, como llevar a cabo una revisión de lo que la historia de los intelectuales ha podido ofrecer hasta el momento en España, con una especial atención a lo referente a la dictadura franquista.

\section{Historia cultural, historia intelectual e historia de los intelectuales}

Es una evidencia que la historia cultural se ha establecido como uno de los campos de producción más generosa en las últimas décadas, aunque siempre acechada por una cierta indefinición de sus límites ${ }^{2}$ y no digamos ya de sus bases epistemológicas, comenzando por

* Este trabajo revisa y actualiza el que, con el título de «Más allá del páramo. La historia de los intelectuales durante el franquismo", se publicó en Carmen Frias, José Luis LEDESMA y Javier RodRIGo (eds.), Reevaluaciones. Historias locales y miradas globales, Zaragoza, Institución Fernando el Católico, 2011, p. 41-76. Agradezco a la Institución Fernando el Católico y a los editores de la obra su generosidad al facilitar esta segunda vida para el texto. A su vez, el trabajo se enmarca en el proyecto HAR2011-25749 «Las alternativas a la quiebra liberal en Europa: socialismo, democracia, fascismo y populismo (1914-1991)», financiado por el Ministerio de Economía y Competitivad. Agradezco a Ferran Gallego los comentarios y sugerencias realizados sobre el texto original.

1 Competentes análisis sobre 1'historia cultural» en España en las últimas décadas en Octavio RuzZ MANJón, «Nuevas orientaciones en historia cultural», en Antonio Morales Moya y Mariano Esteban de Vega (eds.), L'historia contemporánea en España, Salamanca, Ediciones de la Universidad de Salamanca, 1996, p. 197-205; y Helena Hernández SANDOICA, «La historia cultural en España: tendencias y contextos de la última década», en Cercles. Revista d'història cultural, $\mathrm{n}^{\circ} 4$ (2001), p. 5791. Una reciente introducción a la «historia cultural», sus problemas y sus diferentes orientaciones en Peter BuRKe, ¿Qué es la historia cultural?, Barcelona, Paidós, 2006 [edición original inglesa de 2004].

2 La dificultad de definir exactamente qué se entiende por «historia cultural» ha sido repetidamente señalada; a modo de ejemplo, Elena Hernández Sandoica escribia hace algunos años: «una "historia 
la misma dificultad de definir qué se entiende por «cultura» y, por tanto, cuáles deberían ser los objetos de estudio de una «historia cultural»" ${ }^{3}$. En su libro, Formas de historia cultural, Peter Burke ha señalado cómo, sólo en inglés, el número de definiciones del término «cultura» supera los dos centenares, y seguramente se podrían añadir algunas centenas más si se considerasen otras lenguas; de ello se podría derivar, afirma, que «la historia cultural no tiene esencia», lo que le lleva a preguntarse "¿cómo se puede escribir la historia de algo que carece de identidad estable?» $\aleph^{4}$. A responder a esa pregunta, desde la convicción de que tal cosa es posible, dedica las páginas de su libro, pero el problema planteado no carece de enjundia. Y es que, como han indicado recientemente Justo Serna y Anaclet Pons, los miles de trabajos que se han publicado en los últimos años y que se reclaman de «historia cultural» recogen una tal variedad de temas y objetos de estudio «que la voluntad de dar coherencia a todo ello parece condenada al fracaso» ${ }^{5}$. Un peligro de fragmentación del que ya advertía hace unos años Josep Fontana al referirse al, por otra parte, «positivo [...] regreso al territorio de las ideas ${ }^{6}$. No obstante, es labor del historiador separar el grano de la paja y distinguir lo fundamental de lo accesorio; también en lo que hace a la propia producción historiográfica. Y si se obra de esta manera, también en el terreno de la historia cultural acaban perfilándose mejor los temas de trabajo y las líneas metodológicas, pudiéndose establecer jerarquías entre ellos y, consiguientemente, pudiendo separar lo trivial e insustancial de las aportaciones realmente significativas. No tengo la menor duda de que éstas últimas se corresponden con aquellas obras en las que el estudio de los fenómenos culturales se aborda desde una perspectiva social; o dicho de otra forma, cuando se privilegian los enfoques socio-culturales en los análisis históricos. En este último caso, y como ya señaló también Fontana, no estaríamos ante algo nuevo, sino ante una forma de entender la cultura y su historización que puede rastrearse en una tradición historiográfica marxiana que, remontándose a Antonio Gramsci, nos llevaría hasta Edward P. Thompson, y en la que figurarían, entre otros, historiadores de la talla de Christopher Hill? . O que se corresponde también, por citar a uno de los referentes más destacados de la historia cultural en las últimas décadas, con el enfoque de la obra de Roger Chartier.

de la cultura", sea ésta, finalmente, lo que fuere...»; cfr. Elena HERnÁndez SANDOICA, «La historia contemporánea en España: tendencias recientes», en Hispania, LVIII/1, nº 198 (1998) p. 81-82.

3 Una discusión sobre ambas cuestiones - las definiciones de cultura y los objetos de la historia culturalen Justo Serna y Anaclet Pons, La historia cultural. Autores, obras, lugares, Madrid, Akal, 2005, p. 5-18.

4 Peter Burke, Formas de historia cultural, Madrid, Alianza Editorial, 2006, p. 15.

5 Justo Serna, Anaclet Pons, La historia cultural, op. cit., p. 17.

6 La advertencia aparecía en el marco de una dura requisitoria contra una determinada variante de la llamada «historia de las mentalidades» que, en opinión de Fontana, habria prescindido de cualquier vínculo entre las representaciones mentales y la realidad social, haciendo de las primeras «el motor de la historia); véase Josep FontanA, La historia después del fin de la historia, Barcelona, Crítica, 1992, p. 105. Por otra parte, la dispersión temática y metodológica aparece, a ojos de muchos analistas, como un elemento definidor del paisaje historiográfico internacional del último cuarto del siglo XX; véanse, por ejemplo, Enrique Moradiellos, «Últimas corrientes en historia», en Historia social, n 16, 1993, p. 97 113; Elena Hernandez SANDOICA, «La historia contemporánea en España....", p. 89; y Gonzalo PASAMAR, La historia contemporánea. Aspectos teóricos e historiográficos, Madrid, Síntesis, 2000, p. 106 y ss.

7 J. Fontana, La historia..., op. cit., p. 104.

8 Ruiz Manjón, «Nuevas orientaciones...», p. 199; Justo SERnA y Anaclet Pons, La historia cultural, p. 106. Burke advierte, sin embargo, de la problemática relación entre la historia social y la historia cultural, y del peligro de calificar como historio sociocultural prácticamente a cualquier cosa; véase Burke, ¿Qué es la historia cultural?, p. 139-140. 
Una parte de los problemas a los que ha de enfrentarse la historia cultural deriva de lo que es, desde mi punto de vista, uno de sus principales atractivos. Me estoy refiriendo al rico diálogo que mantiene con otras ciencias sociales, de las que los historiadores culturales han extraído tanto repertorios metodológicos como aparato conceptual; a veces, ciertamente, de forma puramente mecánica ( $\mathrm{y}$, entonces, con escaso provecho), pero en no pocas ocasiones de manera bien pensada y asimilada, lo que ha dado lugar al enriquecimiento del instrumental disponible para el historiador. No hace falta insistir en lo mucho que la historia cultural debe a disciplinas como la sociología, la semiótica, la lingüística, el análisis del discurso o la antropología, por citar sólo unas cuantas. Como no hace falta recordar hasta qué punto determinadas formas de adopción de los presupuestos de las mismas han llevado a planteamientos que, en el límite, podían suponer la propia disolución de la historia como ciencia. El llamado "giro lingüístico» sería el caso extremo y más conocido, sin que sea éste ni el momento ni el lugar para ocuparse del mismo?.

Si problemática, al tiempo que rica en resultados, puede resultar la historia cultural, no menos problemas plantea hoy el cultivo de la historia de las ideas. Al menos en la forma más convencional de esa parcela historiográfica, a saber, aquélla que se centra en el estudio de las ideas sin conexión ni real ni aparente con el contexto social, económico y político en que dichas ideas han sido pensadas. Una forma de historia del pensamiento en la que lo único que parece importar es la filiación genealógica del mismo: es decir, en qué autor se fundamentan las ideas de aquél a quien estamos estudiando, y sobre qué otros autores las ideas de éste han influido. Algo absolutamente estéril desde la perspectiva del historiador. En realidad, la historia de las ideas ha de ser encajada en un recipiente más amplio -la historia intelectual-que incluya también el análisis de los contextos históricos en que aparecen los sistemas de pensamiento, su funcionalidad política y social, su eventual organización como ideologías $\mathrm{y}$, no menos importante $-\mathrm{y}$, para lo que a este trabajo se refiere, fundamental- quiénes los elaboran, y en qué condiciones y con qué objetivos, lo que lleva directamente al estudio de los intelectuales. Esa historia intelectual debería atender también a otros asuntos, como los mecanismos de creación y difusión de las ideas dominantes en un determinado momento y lugar, o su recepción por los ciudadanos y la respuesta de éstos, bien sea mediante la aceptación de aquello que se les propone, bien mediante la construcción de modelos alternativos. De hecho, en algún momento, la historia intelectual acabará cruzando los difusos límites de la historia cultural de forma que una acabará siendo parte de la otra, o ambas acabarán siendo en realidad una misma cosa, o partes de una misma $\cos ^{10}$.

9 Para una revisión reciente de la cuestión ( $\mathrm{y}$, más en general, sobre el impacto del postmodernismo sobre la historiografia), véase Serna/Pons, La historia cultural, op. cit., 173-206. Una enérgica defensa de la viabilidad del conocimiento histórico frente al relativismo y el subjetivismo de sus críticos postmodernos en Richard J. Evans, In Defense of History, Nueva York, W.W. Norton, 2000 [1997].

10 No es una novedad esta dificil distinción entre «historia de las ideas», «historia intelectual» e «historia cultural»; Robert Darnton, otra de las figuras de referencia de la reciente historia cultural, clasificaba estas disciplinas hace ya casi tres décadas de la siguiente forma: «the history of ideas (the study of systematic thought, usually in philosophical treatises), intellectual history proper (the study of informal thought, climates of opinion, and literary movements), the social history of ideas (the study of ideologies and idea diffusion), and cultural history (the study of culture in the anthropological sense, including world views and collective mentalités»; pero advertía cómo no pocos autores no hilaban tan fino y optaban por usar términos como historia de las ideas e historia intelectual de forma intercambiable; cfr. Robert DARNTON, «Intellectual and Cultural History», en Michael KAMmEN (ed.), The Past before Us. Contemporary Historical Writing in The United States, Ithaca y Londres, Cornell University Press, 1982 [1980], p. 337. 
En cualquier caso, y como se ha dicho de pasada en el párrafo anterior, esa historia intelectual, preocupada por lo político y por lo social, tendrá que atender en un momento u otro a los sujetos generadores y transmisores de pensamiento, es decir a los intelectuales. O dicho de otra forma: la historia de los intelectuales se configura como un subconjunto de una historia intelectual alejada del puro idealismo y firmemente anclada en el análisis de los contextos socio-políticos en que esos seres humanos a los que llamamos intelectuales viven, piensan y actúan.

La primera dificultad a la que se enfrentará esa disciplina es la definición de su objeto de estudio; es decir, qué se entiende por un «intelectual». Como es bien sabido, se trata de un problema no resuelto (y, probablemente, no resoluble) y que se planteó ya con los primeros estudios que centraron su atención en los intelectuales; o incluso antes: cuando el término «intelectual» empezó a ser utilizado como sustantivo para definir a una determinada categoría de individuos, lo que ocurrió en la Francia de finales del siglo XIX, en el marco de los debates del affaire Dreyfus, y con el archifamoso «J'accuse!» de Émile Zola en la primera página de L'Aurore littéraire, artistique et sociale, el 13 de enero de 1898, como desencadenante ${ }^{11}$.

Como ya ha sido explicado suficientemente, que se generalice entonces el uso del término «intelectual» no significa que no hubiese antes de esa fecha personas que, bajo otras denominaciones, cumpliesen una función semejante a la que van a tener los intelectuales propiamente dichos en el siglo XX. Sin remontarse más allá de lo estrictamente necesario, podemos convenir que los ilustrados del XVIII pueden ser considerados sin necesidad de forzar las cosas como un antecedente claro del intelectual moderno ${ }^{12} . \mathrm{Y}$ a lo largo del siglo XIX encontraremos también ejemplos de lo mismo con cierta facilidad ${ }^{13}$. En todo caso, la

11 Pese a que el término «intelectual» cobra carta de naturaleza en el momento del affaire Dreyfus, la realidad es que su uso como sustantivo era anterior; ya en 1894, por ejemplo, un joven Maurice Barrès había escrito un texto con el título de «La cuestión de los intelectuales»; y por esas mismas fechas un no menos joven Léon Blum utiliza también el término. Por otra parte, y contra lo que acostumbra a decirse, el término intelectual no aparece en el texto de Zola, ni lo utilizan para identificarse los centenares de firmantes de las dos «protestas» que publicó L'Aurore en apoyo de la denuncia de Zola. Fue Georges Clémenceau, redactor jefe del diario, quien, en un artículo publicado el 23 de enero de 1898 , escribió: «AAcaso no son un signo, todos esos intelectuales venidos de todos los rincones del horizonte, reunidos por una idea?»; y como ha señalado Pascal Ory, el uso de la cursiva por el mismo Clémenceau indica lo inhabitual del uso del término; véase Pascal OrY y Jean-François SIRINELLI, Los intelectuales en Francia. Del caso Dreyfus a muestros días, Valencia, Publicacions de la Universitat de València, 2007, p. 15-17 [la cita de Clémenceau en p. 16]. Sobre el episodio Zola, véase también la entrada «Dreyfus (affaire)», que firma Michel Winock y que incluye la relación de firmantes de las sucesivas listas que se adhrieron a la protesta inicial, en Jacques JuLLARD y Michel Winock, Dictionaire des intellectuels français. Les personnes, les lieux, les moments, Paris, Seuil, 2002 [1996], p. 443-461. En otro sentido, Eric Storm ha defendido, con argumentos no desdeñables, que es Barrès y no Zola quien realmente merece el reconocimiento como el primer intelectual en el sentido moderno del término; véase Eric Storm, «Los guías de la nación. El nacimiento del intelectual en su contexto internacional», en Historia y Politica, $\mathrm{n}^{\circ} 8(2002 / 2)$, p. 53-54.

12 Ory/Sirinelli, Los intelectuales en Francia, p. 22; François Dosse, La marcha de las ideas. Historia de los intelectuales, historia intelectual, Valencia, Publicacions de la Universitat de València, 2006, p. 23-25; Josep Picó y Juan Pecourt, «El estudio de los intelectuales; una reflexión», en Revista española de Investigaciones Sociológicas, $\mathrm{n}^{\circ} 123$ (2008), p. 40-41.

13 Así, por ejemplo, un Víctor Hugo en la Francia de Napoleón III [cfr. Dosse, La marcha de las ideas, p. 27], o un Larra o un Galdós en la España decimonónica [cfr. Santos JulıA, «Algunas maneras de ser intelectual en la política», en Antonio Morales Moya (coord.), Las claves de la España del siglo XX. La cultura, Madrid, Sociedad Estatal España Nuevo Milenio, 2001, p. 155-157]. A su vez, Jordi Casassas ha relacionado la aparición del intelectual moderno con «la codificación, y posterior popularización, de un discurso creador de la nación», lo que vale tanto para el Estado republicano francés desde mediados 
literatura sobre el origen de los intelectuales es suficientemente amplia y conocida como para necesitar aquí una explicación más detallada del fenómeno ${ }^{14}$.

Sí parece necesario, por el contrario, recordar que el término «intelectual» no va a significar lo mismo en todas partes, ni su uso va a extenderse con la misma rapidez en todos los países (y me refiero ahora a los de la Europa occidental). La cuestión no es menor, pues esa diferente forma de entender lo que es un «intelectual» ha condicionado también la forma en que en cada país se ha abordado el estudio de ese colectivo ${ }^{15}$. Volviendo a la definición de «intelectual», podemos considerar, con François Dosse, que hay dos grandes formas de interpretar el término: por un lado, la que identifica a los intelectuales como un grupo social determinado (el de aquellas personas que trabajan con su mente y no con sus manos); y por otro, la que los identifica, además de por esa labor no manual, en función de su implicación en la lucha política o, al menos, en el debate público sobre cuestiones de interés colectivo ${ }^{16}$. Es evidente que la primera formulación es tan general que la hace prácticamente inútil (en cualquier sociedad se encontrarían centenares de miles o incluso millones de intelectuales). La segunda forma de entender el término «intelectual» es la que, en general, ha acabado imponiéndose, con todos los matices que se quieran considerar, y desde luego es la que ha hecho fortuna en Francia y, por la directa influencia de la historiografía francesa, en España ${ }^{17}$. Con todo, son tantas las variantes que pueden abrirse en esa implicación en el debate cívico - que sería la característica fundamental del intelectual $^{18}$ - que resulta difícil, por no decir imposible -y, a la postre, inútil-intentar fijar una definición cerrada del término «intelectual» y una caracterización homogénea de ese colectivo, siendo más prudente, como propone Dosse, que la historia de los intelectuales no se limite «a una definición a priori de lo que debería ser el intelectual según una definición

del XIX como para los intelectuales catalanes de la Renaixença que teorizaron las transformaciones sociales, políticas y económicas de la Cataluña de la segunda mitad del siglo XIX; véase Jordi CASASSAS I YMBERT, «Espacio cultural y cambio politico. Los intelectuales catalanes y el catalanismo», en Espacio, Tiempo y Forma, Serie V, Historia Contemporánea, t. 6 (1993) p. 55-80.

14 Para el caso francés, la obra de referencia es, sin duda, Christophe CHARLE, Naissance des «intellectuels» 1880-1900, París, Les Éditions de Minuit, 1990; Charle se remonta en su indagación sobre «les intellectuels avant les "intellectuels"» hasta la Ilustración, pues, como señala, «l'ancêtre le plus direct de 1'"intellectuel" est le philosophe ou l' "homme de lettres" du XVIII" siècle» (p. 20). Para España, véase Carlos Serrano, «Los "intelectuales" en 1900: ¿ensayo general?», en Serge Salaün y Carlos Serrano (eds.), 1900 en España, Madrid, Espasa Calpe, 1991, p. 85-106; y Santos JulıA, «Literatos sin pueblo: la aparición de los "intelectuales" en España", en Studia Historica. Historia Contemporánea, $\mathrm{n}^{\circ} 16$ (1998), p. 107-121.

15 La obra que mejor recoge esas diferencias conceptuales y los diferentes enfoques metodológicos que de aquéllas se derivan es Michel Leymarie y Jean-François Sirinellu (dirs.), L'histoire des intellectuels aujourd'hui, París, Presses Universitaires de France, 2003.

16 Dosse, La marcha de las ideas, op. cit., p. 19.

17 Para el caso español, véase una interpretación del término desde una perspectiva histórica en Santos JuLıA, «Intelectual», en Javier Fernández Sebastián y Juan Francisco Fuentes (dirs.), Diccionario politico y social del siglo XX español, Madrid, Alianza Editorial, 2008, p. 693-701.

18 Michel LeYmarie, Les intellectuels et la politique en France, París, PUF, p. 11-12. Análogamente, en España, José Antonio Marina ha definido al intelectual «como un profesional del mundo de la cultura que utiliza su prestigio para influir sobre la opinión pública en asuntos que afectan a la sociedad»; véase José Antonio MarINA, «El intelectual y el poder», en Rafael del Águila (coord.), Los intelectuales y la política, Madrid, Ediciones Pablo Iglesias, 2003, p. 27. Y uno de nuestros más eminentes cultivadores de la disciplina, como es Elías Díaz, ha dejado escrito que lo que singulariza al intelectual, diferenciándolo de aquéllos que son sólo filósofos, científicos, escritores, cultivadores, en definitiva, de las artes, de las letras o de las palabras, es «su mayor atención y preocupación por la praxis social»; véase Elías DiAz, De la Institución a la Constitución. Política y cultura en la España del siglo XX, Madrid, Trotta, 2009, p. 198 . 
normativa», y que se mantenga «abierta a la pluralidad de estas figuras que, todas, señalan matizaciones diferentes de la forma de tocar el teclado de la expresión intelectual $\rangle^{19}$. Por ejemplo, frente a una cierta inercia a identificar a los intelectuales de forma casi exclusiva con los generadores de ideas y creadores de obras de cultura $-\mathrm{y}$, casi siempre, ubicándolos en el ámbito de las humanidades-, hay que considerar seriamente la existencia de intelectuales vinculados a actividades de tipo profesional, en ocasiones incluso de carácter técnico, cuya influencia sobre la sociedad en la que actúan puede llegar a ser tan importante o más que la ejercida por escritores, filósofos o historiadores, por citar tres colectivos proveedores frecuentes de «intelectuales» ${ }^{20}$.

Contra lo que pueda parecer, la historia de los intelectuales es una disciplina relativamente reciente, por más que puedan rastrearse antecedentes ilustres en tiempos más o menos lejanos. Pero su articulación como rama específica de la historia no se remonta mucho más allá de los primeros años setenta del siglo pasado, siendo en las décadas de los años ochenta y noventa cuando se produce su consolidación y expansión. Esta cronología se ha puesto frecuentemente en relación con el relativo reflujo de aquellos enfoques que habían sido dominantes hasta entonces, caracterizados por la atención a los fenómenos de larga duración, a las estructuras y a los grandes grupos sociales -con un gran peso en todo ello del instrumental cuantitativo-, y que habían mantenido en una situación más o menos marginal a la historia política y a la biografía, dos áreas de trabajo con las que la historia de los intelectuales mantiene una proximidad evidente ${ }^{21}$. No estoy seguro de que pueda establecerse una relación tan mecánica de causa y efecto, y, sin que implique contradicción alguna con el factor anteriormente mencionado, creo más bien que esa nueva atención por el mundo de los intelectuales cabe situarla en el amplio proceso de renovación de la historia que tiene lugar a partir de los años setenta, y que, con todos los peligros de disgregación y fragmentación que ya fueron denunciados en su momento ${ }^{22}$, ha supuesto, en mi opinión, un indudable enriquecimiento de la producción historiográfica, tanto desde el punto de vista de los enfoques metodológicos como de los temas tratados. En esta misma línea, por ejemplo, François Chaubet señalaba muy recientemente cómo la forma en que autores como Christophe Charle, Pascal Ory o Jean-François Sirinelli empezaron a abordar el estudio de los intelectuales a partir de los primeros años setenta tuvo mucho que ver con la influencia que sobre ellos ejercieron autores que, como Roland Barthes, venían denunciando los métodos de una crítica literaria tradicional que analizaba los textos prescindiendo del contexto histórico y social en que habían sido producidos ${ }^{23}$. El traslado

19 Dosse, La marcha de las ideas, op. cit., p. 34.

20 Ilustres ejemplos d'este enfoque en Jeffrey HERF, El modernismo reaccionario. Tecnologia, cultura y politica en Weimar y el Tercer Reich, México, Fondo de Cultura Económica, 1990; o Gilles LE BÉGuEC, La République des avocats, Paris, Armand Colin, 2003. Esta línea de trabajo, la de los intelectualesprofesionales, tiene en nuestra historiografia ejemplos de indudable calidad; véanse, a modo de ejemplo, Francisco Villacorta Baños, Burguesía y cultura. Los intelectuales españoles en la sociedad liberal, 1808-1931, Madrid, Siglo XXI, 1980, y del mismo autor Profesionales y burócratas. Estado y poder corporativo en la España del siglo XX, 1890-1923, Madrid, Siglo XXI, 1989; y Jordi CASASSAS YMBERT, Intel-lectuals, professionals $i$ politics a la Catalunya contemporània (1850-1920). Estudis sobre les bases culturals $i$ estratègiques del catalanisme, Sant Cugat del Vallès, Amelia Romero, editora [colección: Els llibres de la frontera], 1989.

21 Dosse, La marcha de las ideas, op. cit., p. 14.

22 Véanse, entre otros, FontanA, La historia después del fin de la historia; y François Dosse, La historia en migajas. De «Annales» a la «nueva historia», Valencia, Ediciones Alfons el Magnànim, 1988.

23 François CHAUBET, «Histoire des intellectuels, histoire intellectuelle. Bilan provisoire et perspective», en Vingtième siècle. Revue d'histoire, $\mathrm{n}^{\circ} 101$ (2009/1), p. 181-182. 
de esta crítica a la historia intelectual (o a la de las ideas) llevó a interesarse no sólo por la obra de los autores, sino por las circunstancias en que éstos las habían elaborado, así como por la influencia que habían ejercido sobre la sociedad de su tiempo; o dicho de otra forma, a estudiar a los intelectuales y sus obras a partir de enfoques en los que lo político y lo social cumplían una función determinante, dando lugar así al nacimiento de una verdadera «historia de los intelectuales».

\section{La historia de los intelectuales en España}

Por lo que hace a la historia de los intelectuales, la historiografía española no representa un caso singular, sino que se inserta plenamente -si acaso con un pequeño décalage cronológico- en lo que ha sido la actividad de otras historiografías vecinas, aunque, eso sí, fuertemente influida por las líneas de trabajo que ha ido estableciendo la «historia de los intelectuales» francesa en las últimas décadas, especialmente cuando del análisis de la relación entre intelectuales y política se trata; y ahí nombres como los de Charle, Dosse, Leymarie, Ory, Sirinelli o Winock constituyen referencias de primer orden. Tiene que ver esta influencia con algo que se señalaba más arriba, y que es la diferente forma en que se ha entendido el concepto «intelectual» y se ha abordado su estudio en los países de nuestro entorno, lo que a su vez tiene mucho que ver con las diversas tradiciones culturales y académicas de cada país. Así, y pese a que los elementos comunes -en temas de estudio y métodos de trabajo- entre las diferentes historiografías no son desdeñables, un reconocido especialista como Michel Leymarie cree que puede identificarse una forma de hacer compartida - a grandes rasgos- entre los historiadores franceses, italianos y españoles, que los diferenciaría de lo que hacen los británicos y, en menor medida, los alemanes ${ }^{24}$. Por otra parte, no es irrelevante a la hora de explicar esta influencia francesa sobre la historiografía española el hecho de que hayan sido precisamente hispanistas franceses quienes hayan tenido un protagonismo especial en los estudios sobre los intelectuales españoles, y ahí hay que citar a autores como Paul Aubert, Yvan Lissorgues o Carlos Serrano, entre otros. Como no lo es tampoco que uno de los impulsores de ese tipo de estudios, aun siendo español, ejerciese su magisterio desde la universidad francesa de Pau, y me refiero, obviamente, a Manuel Tuñón de Lara.

Con todo, y para lo que hace a l'historia de los intelectuales durante el franquismo, no debe olvidarse el notable influjo que ejercen los historiadores italianos que se han ocupado de los intelectuales en el ventennio fascista, empezando por los escritos de Antonio Gramsci sobre la figura del intelectual y la «organización de la cultura», y siguiendo por autores de obras de referencia indiscutible sobre la cuestión como Renzo de Felice, Mario Isnenghi, Emilio Gentile o Gabriele Turi, por citar sólo a unos pocos eminentes historiadores dentro de una larga lista de muy buenos especialistas en este campo concreto de la historia de los intelectuales italiana. De la misma forma, los trabajos de Alfonso Botti sobre el

24 Sostiene Leymarie que, mientras que las líneas de trabajo en Alemania hoy ya no se alejan demasiado de lo que se hace en Francia, en Gran Bretaña no hay, de hecho, una «historia de los intelectuales» propiamente dicha, sino que se cultiva una «historia intelectual» que se sitúa en el cruce entre una historia de las elites y una historia de la educación, y que quienes se ocupan de los intelectuales son sobre todo los politólogos y los historiadores de la literatura, aunque no falten, obviamente, historiadores a secas. Véase Michel LEYMARIE, «L'histoire des intellectuels aujourd'hui», en Benoit Pellistrandi y JeanFrançois Sirinelli (dirs.), L'histoire culturelle en France et en Espagne, Madrid, Casa de Velázquez, 2008, p. 37-38. 
nacionalcatolicismo han sido determinantes para orientar adecuadamente el análisis de los intelectuales españoles católicos durante todo el siglo $\mathrm{XX}^{25}$.

Paul Aubert, buen conocedor de la cuestión, ha situado los orígenes de la disciplina en España en los años setenta, cuando autores como Vicente Cacho Viu, Elías Díaz o María Dolores Gómez Molleda, entre otros, empezaron a analizar los orígenes intelectuales de la sociedad liberal en España o la recepción del krausismo en nuestro país, y cuando, bajo la dirección del citado Elías Díaz, empezaron a escribirse tesis doctorales sobre intelectuales españoles de renombre (como Besteiro o Fernando de los Ríos). Es entonces también cuando empiezan a proliferar las monografias sobre los principales intelectuales españoles (Unamuno, Costa, Ortega, Azorín, Marañón, Machado, Azaña...), aunque todavía, señala Aubert, desde la perspectiva que podríamos denominar «el autor y su obra», y con escasa atención al contexto social y político en que uno y otra se desenvolvieron ${ }^{26}$. Pero fueron los años ochenta y noventa (de la misma forma que ocurrió en Francia) los que asistieron a la consolidacióny a la proliferación de estudios sobre los intelectuales, abarcando prácticamente todas las parcelas de análisis posibles: desde las obras de los autores a su difusión mediante la prensa y otros medios de comunicación; desde la implicación de los intelectuales en la vida política a los debates en torno a acontecimientos especialmente señalados; desde los estudios de corte generacional a los que sitúan el papel de los intelectuales en el marco de las grandes transformaciones sociales y culturales que acompañaron la entrada de España en la modernidad urbana; desde, en fin, la aparentemente inacabable reflexión sobre el ser de España a los trabajos sobre los intelectuales en ámbitos culturalmente diferenciados de aquéllos que se expresan en castellano, y aquí los estudios sobre intelectuales catalanes han sido sin duda pioneros. Los frutos de todas esas líneas de investigación han sido ricos y abundantes como puede comprobarse en el citado trabajo de Paul Aubert ${ }^{27}$.

Como señalaba hace unos años Helena Hernández Sandoica, a finales del anterior milenio podía darse por consolidada en España una historia de los intelectuales como parcela específica de la historia cultural, «un genero de análisis -escribía Hernández Sandoica- que parte del individuo para llegar al medio que lo sustenta y le da significado. Y que aspira a entenderlo, desde luego, como actor y sujeto de ideas y de proyectos de cierta "calidad creadora" y originalidad, aunque no sea ése su objeto principal ni agote ahí su objetivo político» ${ }^{28}$. Ciertamente era así, pero que la historia de los intelectuales se

25 Alfonso Boтr, Cielo y dinero. El nacionalcatolicismo en España (1881-1975), Madrid, Alianza Editorial, 1992.

26 Paul AuBERT, «Comment fait-on l'histoire des intellectuels en Espagne ?», en Leymarie/Sirinelli (eds.), L'histoire des intellectuels aujourd'hui, p. 66-67; del mismo autor, entre otros titulos, Les intellectuels espagnols et la politique dans le premier tiers du XX $X^{*}$ siècle. Thèse de Doctorat d'État, Université de Bordeaux III, 1995, 1886 p. ; Lille, ANRT, Université de Lille III, 1995; «Los intelectuales en el Poder (1931-1933) : del constitucionalismo a la Constitución », La II República - El primer bienio, Manuel Tuñon de Lara, José-Luis Garcia Delgado (eds.), Madrid, Siglo XXI, 1987, p. 169-231; «Intelectuales y cambio políticon, Los origenes culturales de la II República, Actas del IX Coloquio de Historia Contemporánea dirigido por M. Tuñón de Lara, José-Luis Garcia Delgado ed., Madrid, Siglo XXI, 1993, p. 25-99; « Los intelectuales y la II República», El nacimiento de los intelectuales en España, Ayer, $\mathrm{n}^{\circ}$ 40, Madrid, Asociasión de Historia contemporánea, Marcial Pons, 2001, p. 105-133; «Elitismo y antiintelectualismo en la España del primer tercio del siglo XX», Las élites en la España de Alfonso XIII, (Javier Tusell, Juan Avilés, Julio Gil-Pecharromán eds.), Madrid, UNED, 1994, p.108-139; La frustration de l'intellectuel libéral, Cabris, Sulliver, 2010.

27 Ibid., p. 69-80 (para las diferentes lineas de trabajo que se vienen siguiendo) y p. 84-90 (para una larga relación de trabajos que ilustran lo anterior)

28 Hernández SANDOICA, «La historia cultural en España...», op. cit., p. 74. 
hubiese consolidado como disciplina autónoma no significa que se hubiese completado un programa de trabajo que tuviese bajo su punto de mira una suficiente variedad de temas y de enfoques metodológicos, aplicados además a todos los periodos históricos posibles dentro de la contemporaneidad. Me referiré a un ejemplo concreto, entre otros posibles. Si se analiza la producción historiográfica en este campo se apreciará en seguida -y la exhaustiva relación bibliográfica del anteriormente citado artículo de Paul Aubert es una buena muestra de ello- que un porcentaje altísimo de los estudios que se han venido realizando se han dedicado bien al momento de aparición de la figura del intelectual en España $^{29}$, bien al estudio de los intelectuales en el período que va de la crisis políticocultural del tránsito del siglo XIX al siglo XX hasta la guerra civil, esto es, grosso modo, el primer tercio de la pasada centuria ${ }^{30}$.

Mucho tiene que ver esa opción con algo ya apuntado anteriormente: la influencia de los hispanistas franceses, que, significativamente, han hecho de ese período su ámbito de trabajo preferente; y también la temprana influencia de Tuñón de Lara y su concepción de una historia social de la cultura, y que tuvo igualmente en el primer tercio del siglo XX su espacio de atención dominante. En este sentido, no se puede dejar de insistir en la influencia ejercida por su Medio siglo de cultura española, 1885-1936, o la derivada de los coloquios por él organizados en la Universidad de Pau en los años setenta del pasado $\operatorname{siglo}^{31}$. En todo caso, sin que faltasen obras sobre las etapas posteriores a la guerra civil, ha habido que esperar hasta la presente década para que el estudio de los intelectuales durante el franquismo y la posterior etapa democrática haya empezado a atraer la atención de los historiadores de una forma cuando menos pareja a la dedicada a las décadas iniciales del siglo $\mathrm{XX}^{32}$.

Una característica de la historia de los intelectuales, y en esto España no es ninguna excepción, es el hecho de que su práctica implica a investigadores procedentes de disciplinas diversas, y fundamentalmente a historiadores, sociólogos e historiadores de la literatura. Éstos últimos han tenido $-\mathrm{y}$ siguen teniendo- un protagonismo destacado en el caso español $^{33}$, y en ocasiones sus trabajos han ejercido una influencia de primer orden sobre la

29 Y que tiende a situarse, en paralelo con lo que ocurre en Francia con el affaire Dreyfus, en los años noventa del siglo XIX, concretamente en torno a las movilizaciones que se produjeron con ocasión de los conocidos como procesos de Montjuïc y, más ampliamente, en el marco del debate politico-cultural de nuestra crisis finisecular; a modo de ejemplo, Carlos Serrano, «Los "intelectuales" en 1900...», p. 85-87; y Santos JulıÁ, «Regenerarse o morir: el discurso de los intelectuales», en Mercedes Cabrera y Javier Moreno Luzón (dirs.), Regeneración y reforma. España a comienzos del siglo XX, MadridBilbao, Fundación BBVA, 2002, p. 41-42.

30 En ese periodo se inscriben -con sólo pequeñas aperturas a otras fechas- los artículos del dossier «El nacimiento de los intelectuales en España» publicado en Ayer, $\mathrm{n}^{\circ} 40$ (2000). Más claro aún: de los nueve artículos del dossier «Intelectuales y política en la España contemporánea» publicado en Historia $y$ Política, $\mathrm{n}^{\circ} 8$ (2002/2), sólo uno no corresponde al periodo mencionado (y relativamente, pues se ocupa de la guerra y los primeros años de la dictadura franquista).

31 Manuel Tuñón de LARA, Medio siglo de cultura española, 1885-1936, Madrid, Tecnos, 1970.

32 Así se aprecia en la mayor atención que al tema prestan las revistas especializadas o la creciente cantidad de comunicaciones que se presentan sobre la cuestión en congresos y jornadas. Un buen ejemplo de ello lo constituye el «Expediente: Intelectuales y segundo franquismo», coordinado por Javier MuÑoz Soro, y que se publicó en la revista Historia del presente, $\mathrm{n}^{\circ} 5$ (2005), así como el dossier «Los intelectuales en la Transición», igualmente coordinado por Javier MuÑoz Soro, en Ayer, n 81 (2011/1).

33 Pero tampoco eso constituye un rasgo singular, sino que se da con mayor o menor énfasis en casi todos los paises europeos, y en algún caso de forma bastante extrema: Hans Manfred Bock ha señalado cómo en Alemania este campo de trabajo atrae la atención de la sociología política y de la germanística, hasta el punto, indica, que los germanistas tienden a una ocupación sistemática del mismo; cfr. Hans 
disciplina en su conjunto; baste recordar, como ejemplo paradigmático, el grueso de la obra de José-Carlos Mainer, y muy especialmente su La Edad de plata, así como, para el tema central de este trabajo, su seminal Falange y literatura ${ }^{34}$. Creo que, en la medida que los historiadores no se dejen expulsar de dicho territorio, esa pluralidad de enfoques no puede sino enriquecer nuestro conocimiento de la materia, y tanto los diferentes planteamientos metodológicos como las conclusiones que de ellos se derivan pueden hacernos avanzar mediante el necesario debate intelectual ${ }^{35}$. Por otra parte, bueno será recordar que de la colaboración de un historiador y un historiador de la literatura ha surgido la más sugerente síntesis sobre la vida cultural del franquismo de la que disponemos ${ }^{36}$, lo que no puede sino animar a continuar con esa línea de trabajo multidisciplinar.

En definitiva, creo que puede sostenerse con fundamento que a día de hoy se ha consolidado plenamente en España un área de trabajo en torno a la historia de los intelectuales, y que su producción está llegando a una etapa de madurez. Ello se comprueba no sólo por el creciente volumen y calidad de las publicaciones, sino también por la variedad temática $\mathrm{y}$, muy especialmente, los planteamientos metodológicos que se siguen, y que son perfectamente homologables con los de nuestras historiografias vecinas ${ }^{37}$. Eso no quiere decir que esté todo hecho, ni mucho menos; sigue habiendo lagunas temáticas y temporales que cubrir, y algún trabajo de base fundamental que está por hacer. En relación con esto último, por ejemplo, se hace urgente una labor prosopográfica que nos permita disponer de un instrumento útil de clasificación, descripción e interpretación de los intelectuales españoles en la época contemporánea, del estilo del que ya disponen otros países que están un paso por delante en esta disciplina ${ }^{38}$, o en la línea de los magníficos ejemplos que ya tenemos para la historiografía española contemporáne ${ }^{39}$.

MANFRED BOCK, «Un monde intellectuel polycentrique et apolitique. Regards comparatistes sur les intellectuels allemands et les concepts mis en oeuvre pour écrire leur histoire», en Leymarie/Sirinelli (dirs.), L'histoire des intellectuels aujourd'hii, p. 433.

34 José-Carlos MaINER, La edad de plata (1902-1931). Ensayo de interpretación de un proceso cultural, Barcelona, Asenet, 1975; y Falange y literatura, Barcelona, Labor, 1971.

35 Véase un buen ejemplo de ello en el anteriormente citado «Expediente: Intelectuales y segundo franquismo" publicado en Historia del presente, y muy especialmente las contribuciones del propio coordinador del dossier, Javier Muñoz Soro, y de Jordi Gracia, Santos Juliá y Francisco Sevillano. Sobre la diferencia de objetivos y enfoques metodológicos entre historiadores e historiadores de la literatura, véase Jean-Yves GUÉRIN, «Histoire littéraire, histoire des intellectuels», en Leymarie/Sirinelli (dirs.), L'histoire des intellectuels aujourd'hui, op. cit., p. 145-159.

36 Jordi Gracia y Miguel Ángel Ruiz Carnicer, La España de Franco (1939-1975). Cultura y vida cotidiana, Madrid, Sintesis, 2001.

37 Intentaré explicitarlo al hilo de la reflexión que seguirá sobre la historia de los intelectuales durante el franquismo.

38 Puede ser una buena referencia el ya antes citado Jacques JuILlard y Michel Winock, Dictionaire des intellectuels français. Les personnes, les lieux, les moments, París, Seuil, 2002 [primera edición de 1996; acaba de publicarse una nueva edicición ampliada y revisada]. Como su título indica, no se trata sólo de un diccionario de intelectuales, sino que recoge también información sobre lugares, revistas, acontecimientos y, en general, cuestiones relevantes relacionadas con la actividad de los intelectuales. En España, la obra que más se aproxima a un planteamiento de este tipo es Jordi CASASSAS (ed.), Els intel-lectuals i el poder a Catalumya (1808-1975), Barcelona, Pòrtic, 1999.

39 Ignacio Peiro Martin y Gonzalo Pasamar Alzuria, Diccionario Akal de Historiadores españoles contemporáneos (1840-1980), Madrid, Akal, 2002; Antoni Simon I TARrés (dir.), Diccionari d'historiografia catalana, Barcelona, Enciclopèdia Catalana, 2003. 


\section{Intelectuales y política durante el franquismo}

No hubo que esperar a la muerte de Franco para que se escribiesen y se publicasen los primeros trabajos sobre los intelectuales durante la dictadura ${ }^{40}$. Ciertamente, la mayor parte de quienes frecuentaban la historia intelectual en esos años centraban sus estudios en épocas anteriores, con especial atención a la llamada "generación del 98 », por supuesto, a los intelectuales cuyas obras se consideraban como los fundamentos ideológicos del régimen: Menéndez Pelayo, Vázquez de Mella, Maeztu, etc.. Había también un creciente interés por Unamuno y Ortega, que podían ser reivindicados (sobre todo, una vez muertos) por algunos de los sectores intelectuales y políticos que se movían en el seno del régimen de Franco ${ }^{41}$. También hubo, desde los años sesenta, un interés por el estudio de los intelectuales liberales españoles de finales del XIX y primer tercio del XX, lo que se tradujo en trabajos sobre la recepción del krausismo y la Institución Libre de Enseñanza, entre otros temas de interés ${ }^{42}$. Pero todo ello remitía, como se ve, a intelectuales que desarrollaron la totalidad de su obra (o la parte sustancial de la misma) antes de la guerra civil.

Hay que esperar a finales de los años sesenta y principios de los setenta para que aparezcan los primeros estudios sobre los intelectuales que se formaron o que desarrollaron la mayor parte de su obra ya durante la dictadura. En ese sentido, además de las obras ya mencionadas de Tuñón de Lara y de José-Carlos Mainer, hay que hacer referencia a los trabajos de Elías Díaz ${ }^{43}$ y su empeño no sólo en situar los autores y sus obras, sino, muy especialmente, de explicar por encima de todo el contexto social y político que permite entender determinados debates intelectuales, la aparición de determinadas ideas y la evolución de determinadas trayectorias personales. Unos años antes, Sergio Vilar había realizado una amplia encuesta entre intelectuales y artistas españoles para conocer por dónde soplaban los vientos en ese mundo ${ }^{44}$, mientras que no faltaron en esos primeros

40 Me refiero, claro está, a trabajos académicos. Los había de otro tipo, y desde la época misma de la guerra civil: aquéllos que se dedicaban a denostar a los intelectuales como los verdaderos causantes de la tragedia española, por antiespañoles, anticatólicos y vendidos a tradiciones culturales e ideológicas que nada tenían que ver con las genuinamente españolas. El ejemplo paradigmático de este tipo de planteamientos fue el libro de Enrique SUÑER, Los intelectuales y la tragedia española, Burgos, Editorial Española, 1937; pero trabajos que mantenían este tipo de discurso fueron muy habituales durante la postguerra y hasta bien avanzada la dictadura; véase al respecto, Eduardo MATEO GAMBARTE, «La ideologia del primer franquismo y los intelectuales», en Eurídice, V (1995) p. 81-111.

41 De lo que ha dado cumplida cuenta Ismael SAZ CAMPos en su España contra España. Los nacionalismos franquistas, Madrid, Marcial Pons, 2003. Obviamente, Ortega no sólo era reivindicado por algunos sectores falangistas, sino también por quienes, en los años sesenta, renovaban el interés por la tradición liberal, como podía ser el caso de un Vicente Cacho Viu, que a lo largo de su trayectoria académica dedicó a Ortega diversos trabajos, finalmente recopilados en su Los intelectuales y la política. Perfil público de Ortega y Gasset, Madrid, Biblioteca Nueva, 2000.

42 Vicente CACHo Viu, La Institución Libre de Enseñanza. Orígenes y etapa universitaria (1869-1881), Madrid, Rialp, 1962; Antonio JiMĖnEz-LANDI MARTinez, La Institución Libre de Enseñanza y su ambiente. Los origenes, Madrid, Taurus, 1973.

43 Y muy especialmente a Notas para una historia del pensamiento español actual (1939-1973), Madrid, EDICUSA, 1974; el libro fue reeditado unos años más tarde (sin apenas cambios en el texto, aunque sí con actualización de la bibliografia) con el título Pensamiento español en la era de Franco (19391975), Madrid, Tecnos, 1983.

44 Sergio VILAR, Manifiesto sobre arte y libertad. Encuesta entre los intelectuales y artistas españoles, Barcelona, Fontanella, 1964. En su encuesta, Vilar planteaba seis preguntas sobre la función y el compromiso de los intelectuales y artistas, y respondieron a la misma 79 representantes de ambos colectivos, tanto residentes en España como exiliados, y con diversos grados de proximidad u oposición al régimen de Franco. 
años setenta los intentos de radiografiar el estado de la cultura en España y de establecer los primeros balances sobre sus realizaciones durante el franquismo ${ }^{45}$, un esfuerzo sobre el que se volvería con cierta insistencia en los primeros años de la transición ${ }^{46}$. Se trataba de estudios que se aproximaban a las cuestiones culturales a partir de análisis sectoriales (la literatura, la prensa, la educación, la religión, el cine, el arte, el teatro, la ciencia...), pero que no hacían de los intelectuales propiamente su objeto de atención. Con todo, se publican entonces algunas obras que buscan una aproximación sociológica al mundo intelectual, o que intentan dar cuenta, también desde la sociología, de la aparición de nuevas generaciones de intelectuales durante el franquismo; y estoy pensando en trabajos de, por ejemplo, Benjamín Oltra o Juan F. Marsal ${ }^{47}$.

Como se ve, la mayor parte de estas contribuciones llegaron desde los ámbitos de la sociología ${ }^{48}$ y la historia del pensamiento. Faltaba aún algún tiempo para que los intelectuales empezaran a ser objeto de atención por parte de los historiadores, que por entonces se ocupaban sobre todo de la historia social y de la historia política. Como ya se ha dicho antes, esto no es ninguna anomalía de la historiografía española y se corresponde, quizás con un pequeño desfase temporal, con lo que ocurrió en otros países vecinos. Será en los años ochenta cuando las cosas empiecen a cambiar de forma significativa, como también ocurrió, por ejemplo, en Francia. En efecto, en un texto prácticamente fundacional, Jean-François Sirinelli definió en 1986 la historia de los intelectuales como una histoire en chantier $^{49}$, una historia en obras, en construcción. Sirinelli no sólo defendía las bondades de la historia de los intelectuales para renovar la historia política, sino que trazaba también todo un plan de trabajo a seguir, indicando aquellas líneas de investigación que podían dar lugar a los resultados más óptimos. En buena medida, esas recomendaciones han sido seguidas

45 José Luis Abellán, «Notas sobre la cultura en España: ensayo para un diagnóstico», en La cultura en España (Ensayo para un diagnóstico), Madrid, EDICUSA, 1971, p. 9-50 [el resto del libro incluye trabajos anteriormente publicados por Abellán sobre autores y temas de cultura diversos]; o el número extraordinario dedicado por la revista Triunfo a la cultura española en el siglo XX [Triunfo, $\mathrm{n}^{\circ} 57$ (17 de junio de 1972)] en el que había contribuciones como la de Dionisio RIDRUEJo, «La vida intelectual española en el primer decenio de la postguerra", p. 70-80, luego incluido en su libro Entre literatura y política, Madrid, Seminarios y Ediciones, 1973, p. 15-38; o la de Alfonso SASTRE, «Poco más que anécdotas "culturales" alrededor de quince años (1950-1965)", p. 81-85.

46 Carlos Castilla del Pino et al., La cultura bajo el franquismo, Barcelona, Ediciones de Bolsillo, 1977, que incluía análisis sectoriales de la actividad culturale-historia, filosofia, politica, psiquiatria, literatura, sociología, religión, cine, arte, pedagogía, teatro y ciencia-, precedidos por una introducción que firmaba José $\mathrm{M}^{\mathrm{a}}$ Castellet y que llevaba por título un inquietante «¿Existe hoy una cultura española?»; y Equipo Reseña [coordinador: Norberto Alcover], La cultura española durante el franquismo, Bilbao, Mensajero, 1977, que igualmente abordaba la cuestión a partir de análisis sectoriales a cargo de 32 colaboradores.

47 Benjamin Oltra, Pensar en Madrid. Análisis sociológico de los intelectuales políticos en la España franquista, Barcelona, Barcelona, Euros, 1976; Juan F. Marsal, Pensar bajo el franquismo. Intelectuales y política en la generación de los años cincuenta, Barcelona, Peninsula, 1979.

48 Lo cual no es ninguna sorpresa: como ha explicado Francisco Javier Bobillo de la Peña, la «sociología de los intelectuales» (a diferencia de su historia) tiene una larga tradición que se remonta a Max Weber; cfr. Francisco Javier BoBILLo dE LA PEÑA, La realidad como problema. Estudios sobre intelectuales y politica, Madrid, Tecnos, 1999, p. 74. Un buen ejemplo de esas aproximaciones sociológicas de finales de los años setenta es el libro de Benjamín Oltra, La imaginación ideológica. Una Sociología de los Intelectuales, Barcelona, Ediciones Vicens-Vives, 1978.

49 Jean-François SIRINELLI, «Le hasard ou la nécessité ? Une histoire en chantier: I'histoire des intellectuels», en Vingtième Siècle. Revue d'histoire, n' 9, 1986, p. 97-108. Sirinelli afinó los planteamientos de ese artículo en «Les intellectuels», en René RÉmond (dir.), Pour une histoire politique, París, Seuil, 1988, p. 199-231 [cito por la edición de 1996]. 
en las dos décadas posteriores por la historiografia francesa, y han servido de guía también para trabajos en otros países, entre ellos el nuestro. Entre otros elementos a considerar, Sirinelli indicaba tres líneas de trabajo fundamentalmente: los itinerarios personales o de grupo, la sociabilidad de los intelectuales y las generaciones. Ya se ve que se trata de ámbitos que hoy en día suelen ser frecuentados por los especialistas. Veamos ahora en qué medida y de qué forma han sido seguidos por los estudiosos de los intelectuales durante el franquismo.

Los itinerarios personales remiten, en cierto modo, al estudio biográfico de los intelectuales. Y, en mi opinión, es la biografía una fórmula excelente para estudiar al intelectual desde una perspectiva social y política, que es, como ya he indicado antes, la que realmente puede resultar más fructífera. Dicho de otro modo, la biografía permite situar al intelectual en su época, en su contexto social, político y cultural, y de esa manera entender mejor tanto el contenido de su obra como su actuación en el debate público, que, no lo olvidemos, es lo que hemos convenido que lo convierte realmente en un intelectual ${ }^{50}$. Por otra parte, el estudio de las trayectorias individuales resultará tanto más provechoso si se procede al cruce de las mismas, lo que permitirá establecer, por ejemplo, los momentos en que se da un mayor compromiso de los intelectuales - 0 , por el contrario, cuándo éste disminuye y los intelectuales entran en una cierta inhibición del debate público-, la aparición de determinadas ideas, las ideologías dominantes entre los intelectuales en un momento determinado, etc. ${ }^{51}$.

Se comprenderá, sin embargo, que, habiendo sido considerada la biografía como una especie de género menor durante bastante tiempo, este tipo de trabajos no se hayan prodigado hasta fechas relativamente recientes. De forma que, aunque en esta cuestión nuestra historiografia se ha ido acercando a las pautas europeas, queda todavía mucho camino por recorrer. Sin duda contamos ya con excelentes biografias de algunos de los intelectuales más destacados de las décadas que cubrió la dictadura franquista, pero no se escapará que esa línea de trabajo puede, y debe, dar aún mucho de sí. Por ejemplo -y no pretendo ahora, ni en las páginas que siguen, elaborar un catálogo exhaustivo de publicaciones, sino más bien apuntar algunos mojones destacados en el camino y, sobre todo, advertir de las lagunas más evidentes que tenemos-, no contamos apenas con biografías de los intelectuales que contribuyeron en los primeros años del régimen a su fundamentación teórica e ideológica. Tenemos dos magníficos retratos colectivos de la intelectualidad falangista durante la Segunda República ${ }^{52}$, o una estupenda biografía de uno de los primeros teóricos del fascismo español ${ }^{53}$, así como otra extraordinaria sobre Ernesto

50 Hay innumerables ejemplos de biografias de intelectuales (o de intelectuales-políticos) que responden a esas características de excelencia, y que permiten entender a la perfección tanto al personaje como a la época en que le tocó vivir; en este sentido, y pese a tratarse de una figura de una etapa anterior al franquismo, merece destacarse, por lo que puede tener de modelo para otros trabajos, la reciente biografia de Manuel Azaña que ha publicado Santos Juliá; cfr. Santos Julia, Vida y tiempo de Mamuel Azaña (1880-1940), Madrid, Taurus, 2008.

51 Ory/Sirinelli, Los intelectuales en Francia, op. cit., p. 304

52 Mónica Carbajosa y Pablo Carbajosa, la corte literaria de José Antonio. La primera generación cultural de la Falange, Barcelona, Crítica, 2003; y Mechthild AlBert, Vanguardistas de camisa azul. La trayectoria de los escritores Tomás Borrás, Felipe Ximénez de Sandoval, Samuel Ros y Antonio de Obregón entre 1925 y 1940, Madrid, Visor Libros, 2003.

53 Ferran Gallego, Ramiro Ledesma Ramos y el fascismo español, Madrid, Sintesis, 2005; y, del mismo autor, «La realidad y el deseo. Ramiro Ledesma en la genealogia del franquismo», en Ferran GALLEG y Francisco Morente (eds.), Fascismo en España. Ensayo sobre los origenes sociales y culturales del franquismo, [Mataró], Ediciones de Intervención Cultural/EI Viejo Topo, 2005, p. 253-447. 
Giménez Caballero, el intelectual que introdujo la ideología fascista en España y que más contribuyó a dotar de un aire de vanguardia al fascismo español durante la Segunda República (otra cosa bien diferente será su trayectoria posterior) ${ }^{54}$. Pero nótese que se trata de obras que centran el foco en los años previos a la dictadura franquista. Para los años que siguieron a la guerra civil no hay nada parecido en relación con el falangismo intelectual, con la excepción del caso de Dionisio Ridruejo, sobre el que en los últimos años, y por razones que ahora no hay tiempo de explicar, se ha desatado un considerable interés que ha dado lugar a la publicación de una pequeña parte de su extensísima correspondencia ${ }^{55}$, a la reedición de alguna de sus obras más señaladas ${ }^{56} \mathrm{y}$ a dos biografias que, en conjunto, dejan la figura del escritor y político soriano adecuadamente perfilada ${ }^{57}$. Pero ¿qué se hizo del resto de los miembros de la corte joseantoniana? ¿Dónde están las biografías de destacados intelectuales falangistas como Rafael Sánchez Mazas o Eugenio Montes? ${ }^{58}$ Y no me refiero ahora al análisis literario de sus obras, sino al trazado de sus itinerarios ideológicos y políticos - obviamente, unidos sin remedio a los de su actividadad literaria-. Lo mismo cabe decir de alguien de tanta relevancia en los ámbitos de la edición, la prensa y la censura de las dos primeras décadas de la dictadura como el viejo jonsista Juan Aparicio, no precisamente un amigo de los intelectuales, pese a que él mismo no dejara de ser un auténtico intelectual funcionario del régimen. Pero si de verdaderos intelectuales de fuste se trata-Aparicio, claro, no lo es-, en los años cuarenta no hubo más sólido sustentador del nacionalsindicalismo que Pedro Laín Entralgo. Su trayectoria, como las de Antonio Tovar, Gonzalo Torrente Ballester y otros eminentes miembros del grupo que Dionisio Ridruejo aglutinó alrededor suyo en el Burgos de 1938, a la sombra de la Jefatura Nacional de Propaganda, fue larga, sinuosa y compleja. La mayoría de ellos están a la espera de que un biógrafo les dedique la atención que indudablemente merecen, y sólo Laín escapa en parte a esa situación de abandono ${ }^{59}$. Ciertamente hay otras excepciones, y algunos de los

54 Enrique Selva, Ernesto Giménez Caballero. Entre la Vanguardia y el Fascismo, Valencia, Pre-Textos/ Institució Alfons el Magnànim, 2000.

55 Dionisio Ridruejo, Materiales para una biografia, selección y prólogo de Jordi Gracia, Madrid, Fundación Santander Central Hispano, 2005; Jordi Gracia (ed.), El valor de la disidencia. Epistolario inédito de Dionisio Ridruejo. 1933-1975, Barcelona, Planeta, 2007.

56 Casi unas memorias, edición al cuidado de Jordi Amat, Barcelona, Península, 2007; y Escrito en España, edición y estudio introductorio de Jordi Gracia, Madrid, Centro de Estudios Políticos y Constitucionales, 2008.

57 Francisco Morente, Dionisio Ridruejo. Del fascismo al antifranquismo, Madrid, Sintesis, 2006; y Jordi Gracia, La vida rescatada de Dionisio Ridruejo, Barcelona, Anagrama, 2008; que se suman a la anterior de Manuel Penella, Dionisio Ridruejo, poeta y político. Relato de una existencia auténtica, s.l., Cajaduero, 1999.

58 De Sánchez Mazas se ha publicado recientemente una biografia que, sin embargo, está lejos de agotar la vida y el pensamiento del personaje; cfr. Alfonso Carlos SAIZ VALDIVIESo, Rafael Sánchez Mazas. El espejo de la memoria, Bilbao, Muelle de Uribitarte Editores, 2010. Lamentablemente, continua inédita la tesis de Mónica Carbajosa Pérez, La prosa del 27: Rafael Sánchez Mazas, Universidad Complutense de Madrid, 1995.

59 Hasta hace muy poco tiempo, sobre Laín sólo se disponia de algunas breves aproximaciones biográficas: Agustín Albarracín Teulón, Retrato de Pedro Laín Entralgo, Barcelona, Círculo de Lectores, 1988; y Antonio Piñas Mesa, Biografia de Pedro Laín Entralgo (1908-2001), Madrid, Fundación Emmanuel Mounier, 2007. También tenía interés la obra colectiva La empresa de vivir. Estudios sobre la vida y la obra de Pedro Laín Entralgo, Barcelona, Galaxia Gutenberg, 2003. Muy recientemente, se ha publicado una detallada biografia del personaje: Diego Gracia, Voluntad de comprensión. La aventura intelectual de Pedro Laín Entralgo, Madrid, Triacastela, 2010. No obstante, aunque la biografia de Gracia es de enorme interés para seguir la evolución de la trayectoria intelectual y cientifica de Laín, resulta claramente insuficiente para entender su actuación politica; Gracia-discípulo de Laín, a quien sucedió 
profesores universitarios, escritores y artistas que se movieron en las proximidades de ese círculo de intelectuales falangistas sí han sido objeto de estudios biográficos que merecen ser reseñados: es el caso de escritores como Edgar Neville o universitarios como Martí de Riquer $^{60}$. Caso aparte sería el de Julián Marías, que desarrolla en los años de la postguerra una obra al margen de las instituciones académicas (en las que estuvo vetado), que, por eso mismo, se mantuvo alejado del régimen, pero que, al tiempo, mantuvo una proximidad personal con algunos de los miembros de aquel falangismo intelectual ${ }^{61}$.

No mucha mejor suerte han tenido los que fueron en los años de la guerra y la postguerra los rivales intelectuales de aquel «grupo de Burgos»: los hombres que, viniendo de Acción Española, representaron la alternativa monárquica, católica y reaccionaria al falangismo radical de Ridruejo y los suyos. Personajes como Pedro Sainz Rodríguez o José María Pemán han atraído la atención de los historiadores y cuentan con trabajos sobre su vida pública e intelectual, aunque no siempre sobre el conjunto de su trayectoria ${ }^{62}$. Sin embargo, tampoco en este campo se ha completado el trabajo: itinerarios como el de Eugenio Vegas Latapié, por ejemplo, merecen una atención que hasta el momento no han recibido adecuadamente, y del propio Sainz Rodríguez falta un trabajo sobre su actuación intelectual y política tras la guerra civil. Sin embargo, a diferencia de lo que ocurre con el grupo de intelectuales falangistas, los intelectuales católicos integristas vinculados al Opus Dei y aglutinados en torno a la figura de Rafael Calvo Serer sí cuentan con un estudio de notable calado, que sirve tanto de retrato de grupo como de biografía político-intelectual del propio Calvo ${ }^{63}$; no obstante, están por hacer las biografías personales de miembros de esta corriente tan importantes como el citado Calvo Serer, Florentino Pérez Embid o José María Albareda ${ }^{64}$. Próximo a este grupo, pero con una trayectoria académica e ideológica singular, se situaría Jaume Vicens Vives, historiador e intelectual de primer orden en la España de los años cincuenta, sobre cuya figura, y especialmente al hilo del centenerario

en su cátedra de Historia de la Medicina- se acoge acríticamente a la (indulgente) interpretación que el propio Laín hizo de sí mismo en su Descargo de conciencia (1930-1960) (Barcelona, Barral Editores, 1976) y hace todos los esfuerzos del mundo para elejar a su biografiado de la caracterización de fascista, incluso en los años en que ni el propio Lain dudaba de serlo. Todo lo contrario del planteamiento de José Alsina Calvés en Pedro Laín Entralgo. El político, el pensador, el científico, Molins de Rei, Ediciones Nueva República, 2010; Alsina, desde posiciones de afinidad intelectual e ideológica con el Laín falangista, no sólo no enmascara las posiciones políticas de su biografiado sino que reivindica su etapa de compromiso con el fascismo, al tiempo que celebra la, en su opinión, coherente trayectoria política y personal de Laín durante toda su vida; en su libro, Alsina traza un breve esbozo biográfico del personaje y dedica las páginas más interesantes al análisis del pensamiento de Laín.

60 Juan Antonio Rios Carratalá, Una arrolladora simpatía. Edgar Neville: de Hollywood al Madrid de la posguerra, Barcelona, Ariel, 2007; Cristina GATEll y Glòria SolER, Martí de Riquer: viure la literatura, Barcelona, La Magrana, 2008.

61 Helio Carpintero, Julián Marias. Una vida en la verdad, Madrid, Biblioteca Nueva, 2008.

62 Julio Escribano Hernández, Pedro Sáinz Rodríguez, de la Monarquía a la República, Madrid, Fundación Universitaria Española, 1998; José Ramón LóPEZ BAuSELA, La contrarrevolución pedagógica en el franquismo de guerra. El proyecto político de Pedro Sainz Rodríguez, Madrid, Biblioteca Nueva y Ediciones de la Universidad de Cantabria, 2011. Gonzalo Álvarez ChILlida, José Maria Pemán. Pensamiento y trayectoria de un monárquico, Cádiz, Universidad de Cádiz, 1996; Javier Tusell y Gonzalo Álvarez Chillida, Pemán. Un trayecto intelectual desde la extrema derecha hasta la democracia, Barcelona, Planeta, 1998;

63 Onésimo Diaz Hernandez, Rafael Calvo Serer y el Grupo Arbor, Valencia, Publicacions de la Universitat de València, 2008.

64 Sobre Albareda se dispone de la hagiografia que le dedicó Enrique GutítrREz Ríos, José María Albareda. Una época de la cultura española, Madrid, Editorial Magisterio Español, 1970 -muy apropiadamente publicada en la colección «Novelas y Cuentos» de la citada editorial-. 
de su nacimiento y cincuentenario de su muerte conmemorados a lo largo del año 2010, tenemos un conocimiento cada vez más riguroso ${ }^{65}$.

Si avanzamos algo en el tiempo de la dictadura, algunos de los intelectuales que protagonizaron su segunda mitad cuentan ya con estudios biográficos reseñables. Así, por ejemplo, Joaquín Ruiz Giménez, de quien, no obstante, no está todo dicho y aún no se ha escrito la biografía definitiva, suponiendo que tal cosa exista ${ }^{66}$. Igualmente, Aranguren o Tierno, por citar dos intelectuales que tendrán una innegable influencia en el tardofranquismo y durante la transición y sobre los que hay además abundantes trabajos que se aproximan a su obra o a momentos concretos de su actuación política como intelectuales ${ }^{67}$. O los casos de Manuel Sacristán y Alfonso Carlos Comín, que hicieron el camino desde el falangismo (el primero) y el catolicismo (el segundo) hasta el marxismo, convirtiéndose en referentes intelectuales de primer orden para la izquierda que combatía a la dictadura ${ }^{68}$. Y no faltan

65 Con todo, sigue siendo fundamental Josep Maria Muñoz i Lloret, Jaume Vicens i Vives (19101960): una biografia intel-lectual, Barcelona, Edicions 62, 1997. El Año Vicens ha dejado algunas contribuciones muy relevantes para el conocimiento de su vida y obra intelectual y política; véanse, Lola Harana (coord.), Jaume Vicens Vives, mestre d'historiadors, Barcelona, Publicacions de la Universitat de Barcelona, 2010; Jaume Vicens i Vives. Visions sobre el seu llegat, edición e introducción de Jaume Sobrequés i Callicó y Mercè Morales i Montoya, Barcelona, Editorial Base, 2010; y Miquel Àngel MARIN Gelabert, A través de la muralla. Jaume Vicens Vives y la modernización del discurso histórico, Barcelona, Vicens Vives, 2010.

66 Valen de momento José Luis GonzÁlez BALAdo, Ruiz-Giménez, talante y figura. Trayectoria de un hombre discutido, Madrid, Ediciones Paulinas, 1989; Javier MuÑoz Soro, «Joaquín Ruiz-Giménez o el católico total (apuntes para una biografia política e intelectual hasta 1963)", en Pasado y Memoria. Revista de Historia Contemporánea, $\mathrm{n}^{\circ} 5$ (2006) p. 259-288; y del mismo autor «Entre héroes y mártires. La síntesis católica de Joaquín Ruiz-Giménez (1939-1951)», en Ferran Gallego y Francisco Morente (eds.), Rebeldes y reaccionarios. Intelectuales, fascismo y derecha radical en Europa, 1914 1956, [Mataró], El Viejo Topo, 2011, p. 339-369. Muy recientemente, María Paz Pando Ballesteros ha publicado Ruiz-Giménez y Cuadernos para el Diálogo. Historia de una vida y de una revista, Salamanca, Libreria Cervantes, 2009, pero en la que el tratamiento biográfico del político madrileño ocupa un espacio relativamente breve, centrándose el trabajo en la revista, el entramado empresarial que la hizo posible y los sectores ideológicos que colaboraron en el proyecto, con especial atención a los democristianos; de hecho, la misma autora había publicado unos años antes su tesis doctoral con el título de Los democristianos y el proyecto político de Cuadernos para el Diálogo, 1963-1969, Salamanca, Ediciones de la Universidad de Salamanca, 2005, donde ya abordaba esas mismas cuestiones.

67 Sobre Aranguren puede consultarse Feliciano BlAzquez, José Luis L. Aranguren. Medio siglo de la Historia de España, Madrid, Ethos, 1994; y Cristina Hermida del Llano, José Luis L. Aranguren: estudio sobre su vida, obra y pensamiento, Madrid, Dykinson, 1997; resulta fundamental, por otra parte, el monográfico que le dedicó la revista Isegoria, n 15 (1997). Sobre Tierno, además del monográfico sobre su trayectoria política e intelectual publicado por la revista Sistema, n 71-72 (1986), véase Raúl Morodo, Tierno Galván y otros precursores politicos, Madrid, Ediciones El País, 1987; Mario RuIz Sanz, Enrique Tierno Galván: aproximación a su vida, obra y pensamiento, Madrid, Dykinson, 1997; Jorge Novella SuÁrez, El proyecto ilustrado de Enrique Tierno Galván, Madrid, Centro de Estudios Políticos y Constitucionales, 2001; y -aunque en este caso más parece un ajuste de cuentas que una biografia-César Alonso de los Rios, La verdad sobre Tierno Galván, Madrid, Anaya \& Mario Muchnik, 1997.

68 Sobre Sacristán, «Manuel Sacristán Luzón 1925-1985», monográfico de Mientras Tanto, n $30-31$ (1987); Salvador López ArNal, Acerca de Manuel Sacristán, Barcelona, Destino, 1996; Juan-Ramón Capella, La práctica de Mamuel Sacristán. Una biografia politica, Madrid, Trotta, 2005; y Salvador López Arnal e Iñaki VÁzquez (eds.), El legado de un maestro. Homenaje a Manuel Sacristán, Barcelona, FIM-Ediciones de intervención cultural, 2007. Además, resulta imprescindible Integral Sacristán, [Mataró], El Viejo Topo, 2006: documental de Xavier Juncosa sobre el pensador y político marxista (4 DVD), acompañado del libro Joan BenACH, Xavier Juncosa y Salvador López ARnAL (eds.), Del pensar, del vivir, del hacer. Escritos sobre "Integral Sacristán» de Xavier Juncosa, [Mataró], Ediciones de Intervención Cultural/El Viejo Topo, 2006. Para Comín, véase Francisco J. CarmonA, Cambios 
tampoco las biografias de escritores que tuvieron un cierto grado de compromiso político, ya fuese de vinculación con el régimen de Franco, ya de rechazo y oposición al mismo ${ }^{69}$. Queda, sin duda, mucho por hacer en esta línea de trabajo (la lista de intelectuales, sobre todo de la oposición, que merecerían atención biográfica sería ciertamente larga), pero conviene señalar que está viva y que permitirá en los próximos años ir completando los itinerarios personales de los principales intelectuales españoles durante la dictadura, y con ello se irán poniendo los fundamentos que permitirán seguir construyendo una historia de los intelectuales en ese período ${ }^{70}$.

De poco serviría, sin embargo, quedarse sólo en el esbozo de los itinerarios individuales, que es el objeto habitual de la biografía. En el programa marcado en su momento por Sirinelli y del que me hacía eco más arriba, el estudio de la sociabilidad de los intelectuales aparecía como otro elemento esencial para la reconstrucción de su historia. Un concepto, éste de «sociabilidad», tomado de Maurice Agulhon, quien lo definía como «una aptitud para vivir en grupo y para consolidar los grupos por la constitución de asociaciones voluntarias $\rangle^{71}$, y que muchos historiadores han incorporado a sus análisis sobre el mundo de los intelectuales. Se trataría aquí de establecer las redes de relación entre intelectuales en un lugar y momento determinados, lo cual lleva al estudio de los ámbitos en los que esas relaciones se establecen y desarrollan, y que van desde las editoriales y revistas hasta los congresos, pasando por los cafés, las tertulias o las escuelas literarias, y sin olvidar la firma de manifiestos y peticiones ${ }^{72}$. No obstante, no han faltado las advertencias sobre los peligros que pueden derivarse también de este tipo de enfoques. Así, tras reconocer las innegables virtudes de esta orientación metodológica, François Chaubet ha señalado, siguiendo a Christophe Charle, el peligro de quedarse en la visión «micro», de pequeña escala, de ensimismarse en el estudio de la red de sociabilidad de un grupo de intelectuales perdiendo de vista el contexto más general, es decir, la interrelación entre el grupo analizado y otros elementos de referencia más amplios ${ }^{73}$. Por otra parte, parece ocioso recordar

en la identidad católica: la juventud de Alfonso Carlos Comín, Madrid, Libertarias-Prodhufi, 1995; y Francisco Martínez Hoyos, La cruz y el martillo. Alfonso Carlos Comín y los cristianos comunistas, s.l., Ediciones Rubeo, 2009.

69 Así, no faltan biografias que sitúan al escritor en su época y se extienden sobre su actuación política; a modo de ejemplos, y sin ánimo de agotar nada: sobre Josep PLA, Xavier FeBrés, Josep Pla: Biografia de l'homenot, Barcelona, Plaza \& Janés, 1990; y Cristina BADosA, Josep Pla. Biografia del solitari, Barcelona, Edicions 62, 1996; sobre Carles Riba: Jaume MedinA, Carles Riba (1893-1959), Barcelona, Publicacions de I'Abadia de Montserrat, 1989, 2 vols.; o, muy recientemente, sobre Luis Martín-Santos: José Lazaro, Vidas y muertes de Luis Martín-Santos, Barcelona, Tusquets, 2009.

70 Buena prueba del creciente interés por este ámbito de trabajo es la aparición de obras colectivas en las que se esbozan itinearios personales de intelectuales y políticos unidos por algún elemento común; a título de ejemplo, dos obras muy recientes: Alejandro QuIroga Fernández de Soto y Miguel Ángel DEL Arco Blanco (eds.), Soldados de Dios y apóstoles de la Patria. Las derechas españolas en la Europa de entreguerras, Granada, Comares, 2010; y Xosé M. NúÑez SeiXas y Fernando Molina (eds.), Los heterodoxos de la patria. Biografias de nacionalistas atípicos en la España del siglo XX, Granada, Comares, 2011.

71 Dosse, La marcha de las ideas, op. cit., p. 57.

72 Ibid., p. 51-57; Снаuвet, «Histoire des intellectuels...», op. cit., p. 184.

73 François CHAUBEт, «Sociologie et histoire des intellectuels», en Leymarie/Sirinelli (dirs.), L'histoire des intellectuels aujourd 'hui, p. 190. Chaubet defiende los planteamientos de Pierre Bourdieu-su concepto de "campo»-como la fórmula más adecuada para esquivar ese peligro. Una advertencia similar en François Dosse, «De l'histoire des idées à l'histoire intellectuelle», en LeYmarie/SirInelLI (dirs.), L'histoire des intellectuels aujourd'hui, p. 179; $\mathrm{y}$ en PICó/PECOURT, «El estudio de los intelectuales...», p. 38. 
que este enfoque lleva a una inevitable aproximación del historiador a los instrumentos metodológicos y conceptuales de la sociología.

Sin duda, ha sido el estudio de las revistas el que más juego ha dado a la hora de analizar estas redes de sociabilidad intelectual. No es de extrañar que sea así puesto que, como ha indicado François Dosse, «las revistas, que son uno de los soportes esenciales del campo intelectual, pueden ser [...] espacios muy valiosos para analizar la evolución de las ideas en tanto que lugares de fermentación intelectual y de relaciones afectivas ${ }^{74}$. Y es que, como ha señalado Jean-François Sirinelli, la revista «estructura el campo intelectual con sus mecanismos antagónicos de adhesión - por las amistades que subyacen, las fidelidades que consigue y la influencia que ejerce-y de exclusión -por las posiciones adoptadas, los debates suscitados y las escisiones aparecidas $\rightarrow\rangle^{75}$. Pero quizás quien mejor ha explicado la función que desempeñan las revistas para los intelectuales ha sido Michel Winock, al hilo de su magnífico estudio sobre la revista Esprit. Señala Winock que la revista "se distingue del libro y del periódico por ser el medio de expresión propio de los intelectuales; ciertamente, los intelectuales escriben libros y colaboran eventualmente en un periódico, pero, contrariamente a éste, la revista es menos sumisa al mercado, a la actualidad, al ritmo sincopado de la prensa cotidiana, y contrariamente al libro, la revista es una empresa colectiva»; el modelo de una revista intelectual se correspondería, añade Winock, con lo que fue La Revue blanche (entre 1889 y 1903): un «cenáculo independiente, lugar de encuentros e intercambios, donde se tejen solidaridades, e incluso complicidades»; en definitiva, «la revista deviene un lugar de reunión, una bandera, una capilla, para los intelectuales -contrariamente a las revistas tradicionales que intercambian las firmas entre ellas. Pertenecer a una revista, a su comité de redacción, es, para el combatiente de las ideas, como pertenecer a un partido ${ }^{76}$.

Todo lo cual, como es evidente, convierte a las revistas en un territorio especialmente interesante de análisis, susceptible de aportar información de primer orden tanto sobre las actividades y posiciones de intelectuales concretos como de las relaciones ideológicas, políticas o simplemente de afinidad cultural o personal que se puedan dar entre ellos. Pues bien, esta línea de trabajo ha sido también provechosamente utilizada por los investigadores españoles en los últimos años en lo que hace referencia a las revistas políticas publicadas durante el franquismo. Sobre esta cuestión, deben hacerse, sin embargo, algunas precisiones. En este trabajo se está asumiendo la interpretación del «intelectual» como la persona que, arropada en un cierto prestigio en su campo profesional -sea éste el que sea, pero, obviamente, relacionado con el manejo de ideas y conceptos-, interviene en el debate público con el fin de influir en la orientación de la opinión (al menos, de la más formada) en cuestiones de interés colectivo. Esta forma de concebir la figura del

74 Dosse, La marcha de las ideas, op. cit., p. 51.

75 Ory/SirInelli, Los intelectuales en Francia, op. cit p. 305.

76 Michel Winock, "Esprit». Des intellectuels dans la cité (1930-1950), París, Seuil, 1996 [1975], p. 13 [la traducción es mia]. Esta línea de trabajo ha sido especialmente cultivada en Francia, tanto por lo que hace al estudio de las revistas, como al análisis de grupos de intelectuales unidos por elecciones afectivas e ideológicas; véanse, a modo de ejemplo, y en relación con los intelectuales franceses que se dejaron tentar por el fascismo Pierre-Marie Dioudonnat, «Je suis partout» 1930-1944. Les maurrassiens devant la tentation fasciste, Paris, La Table Ronde, 1973; Jean-Louis LouBET DEL BAYLE, Les non-conformistes des années 30. Une tentative de renouvelement de la pensée politique française, Paris, Éditions du Seuil, 1969; Nicolas KessLER, Histoire politique de la Jeune Droite (1929-1942) Une révolution conservatrice à la française, París, L'Harmattan, 2001; y Olivier DARD, Les rendez-vous manqué des relèves des années 30, París, Presses Universitaires de France, 2002. 
«intelectual» parece exigir unas determinadas condiciones para ese debate público que sólo las sociedades democráticas están en condiciones de ofertar. No era el caso, ocioso es decirlo, del régimen franquista, pero, como parece también evidente, la falta de libertades públicas, empezando por la de expresión y de libre circulación de las ideas, no acabó en España ni con los intelectuales ni con sus debates públicos ${ }^{77}$. Lo que ocurrió, claro está, es que sólo una parte de la intelectualidad podía expresarse con amplia libertad -en la medida que lo que defendía estaba en consonancia con lo que el régimen representaba y sostenía-, mientras que otra parte se veía obligada al silencio o a expresarse con enormes cautelas y limitaciones (por no hablar de quienes se encontraban en el exilio $-\mathrm{y}$ no por ello eran menos intelectuales españoles-, por lo que sus aportaciones al debate de ideas en España quedaban prácticamente imposibilitadas, más allá de la circulación clandestina de libros y revistas) ${ }^{78}$. Quiero decir con esto que el estudio de las revistas políticas durante el franquismo debe ser abordado tomando en consideración cuáles eran las condiciones en que eran publicadas y, consiguientemente, cuáles eran los límites de los debates que podían

77 Como permiten comprobar algunos libros absolutamente fundamentales para el conocimiento de los debates político-intelectuales de estos años; cfr. Álvaro FERRARY, El franquismo: minorias políticas y conflictos ideológicos (1939-1956), Pamplona, Eunsa, 1993; José Andrés-Gallego, ¿Fascismo o Estado católico? Ideología, religión y censura en la España de Franco 1937-1941, Madrid, Ediciones Encuentro, 1997; SAZ CAmpos, España contra España, op. cit. ; y Santos Julı̇, Historias de las dos Españas, Taurus, Madrid, 2004;

78 Cualquier reflexión sobre los intelectuales españoles durante el franquismo ha de tener presente, en mi opinión, a los intelectuales en el exilio; y no sólo atendiendo a las interrelaciones que se dieron (sobre todo a partir de mediados de los años cincuenta) entre intelectuales del interior y quienes estaban fuera de España, sino por la importancia de la reflexión que éstos llevaban a cabo desde lejos, pero sin perder de vista ni un momento la situación interna de su pais de origen. La bibliografia al respecto es inmensa, y no puede ser ni siquiera esbozada en el limitado espacio de una nota al pie, pero se nos permitirá citar al menos tres recientes -y sugerentes- aproximaciones a la cuestión, con posiciones, por lo demás, bastante alejadas entre si: Mari Paz BaliBrea, Tiempo de exilio. Una mirada critica a la modernidad española desde el pensamiento republicano en el exilio, [Mataró], Montesinos, 2007; Fernando LARRAz, El monopolio de la palabra. El exilio intelectual en la España franquista, Madrid, Biblioteca Nueva, 2009; y Jordi Gracia, A la intemperie. Exilio y cultura en España, Barcelona, Anagrama, 2010. Uno de los debates más presentes en las últimas producciones sobre el exilio intelectual trata sobre hasta qué punto su legado se ha incorporado o no a la cultura democrática actual. Asi, por ejemplo, Mari Paz Balibrea plantea su trabajo a partir de una radical disconformidad con las tesis sostenidas por Jordi Gracia en un libro anterior -La resistencia silenciosa. Fascismo y cultura en España (Barcelona, Anagrama, 2004)- que Balibrea interpreta (desde mi punto de vista, de forma excesiva) como el intento de Gracia de fundar la cultura del antifranquismo -y, por extensión, de la etapa que siguió a la dictadura- de forma casi exclusiva en los intelectuales, algunos de ellos falangistas, que mantuvieran viva la llama liberal (aunque fuera de manera silenciosa) en los quince años que siguieron al final de la guerra civil, y frente a lo cual ella propone la cultura del exilio como la verdaderamente forjadora de una cultura democrática anti y post-franquista, que habría quedado marginada y que no se correspondería con la cultura liberal que resultó hegemónica tras la muerte del dictador (véanse, especialmente, las p. 23-31 de su obra). El propio Gracia, en su A la intemperie, sale al paso de ese tipo de planteamientos sosteniendo que «la democracia ha cumplido ampliamente su justo afán de reivindicación de la obra y el drama del exilio, y ha restituido ambas cosas a la cultura viva del presente» (p. 20). A su vez, muy recientemente, al reflexionar sobre las políticas institucionales sobre la memoria del antifranquismo, Javier Muñoz Soro ha señalado cómo «el exilio ha suplantado la memoria del pasado antifranquista y su cultura, médula resistencial contra el franquismo, ha sido despojada de los elementos más políticos y conflictivos para otorgarle una unidad en parte ficticia, la de una especie de patrimonio nacional sobre el cual se ha edificado la democracia. El recuerdo de la cultura antifranquista ha sido sobre todo el recuerdo de los intelectuales que evolucionaron desde el franquismo, o de los liberales que volvieron a su ser, puente con las nuevas generaciones que protagonizaron la democracia»; cf. Javier Muñoz Soro, «De los intelectuales y su pasado: usos públicos de la cultura antifranquista», documento de trabajo presentado en el Seminario de Historia de la Fundación José Ortega y Gasset, 17 de junio de 2010, p. 32. 
acoger en sus páginas ${ }^{79}$. Teniendo en cuenta todo ello, es evidente, y así ha sido puesto de manifiesto por los especialistas, que hay un antes y un después de la aprobación de la Ley de Prensa de 1966, que posibilitó, en el marco de unas condiciones sociales y culturales nuevas, una expansión de este tipo de prensa ${ }^{80}$, y ello a pesar de (más que gracias a) lo que pudo ser la intención del ministro Fraga o lo que establecía el propio articulado de la ley ${ }^{81}$. En cualquier caso, la nueva situación de la prensa y los medios audiovisuales en España seguía estando lejos de lo que podríamos considerar como verdadera libertad de expresión ${ }^{82}$; lo que no quita para que se diesen las condiciones que permitieron la floración de una cierta prensa periódica, tanto de información general como de información política, que sirvió para canalizar la intervención de los intelectuales contrarios al régimen en el debate público y para crear un ámbito de poder cultural que, en mayor o menor medida, se escapaba del estricto control que hasta ese momento había ejercido el Estado en esa parcela ${ }^{83}$. Nada que ver, por tanto, con lo que fue el mundo de las revistas culturales y políticas de los años cuarenta y cincuenta, lo que no es óbice para que el estudio de estas últimas sea igualmente interesante y nos dé claves para entender el juego de los intelectuales afines al régimen, incluyendo los procesos que condujeron a la expresión de las primeras disidencias en el seno del mismo. De hecho, a pesar de que hay aproximaciones al estudio de algunas de las principales revistas de las dos primeras décadas del franquismo, en pocos casos se ha procedido a un análisis sistemático de las mismas $-\mathrm{y}$, desde luego, no se ha hecho desde su consideración de ámbito de sociabilidad de los intelectuales que en ellas colaboraban-. Así, por ejemplo, hasta muy recientemente no hemos dispuesto de un estudio a fondo de Escorial, la revista cultural y política más importante de la España de la inmediata postguerra $^{84}$, y la que mejor permite analizar las redes de sociabilidad de la intelectualidad

79 Una interesante reflexión sobre estas cuestiones en la inmediata postguerra en Francisco SEVILLANO CALERo, «Propaganda y dirigismo cultural en los inicios del Nuevo Estado», en Pasado y Memoria. Revista de Historia Contemporánea, $\mathrm{n}^{\circ} 1$ (2002), p. 81-110. En un texto reciente, José Carlos Mainer, refiriéndose a la posibilidad de un verdadero debate intelectual en los años que siguieron al final de la guerra, prefiere hablar de «un simulacro de formación de opinión ejercido por falsos intelectuales»; véase, José Carlos MAINER, «La nueva intelligentsia franquista y Europa», en Francesc Vilanova i VilaAbadal y Pere Ysàs i Solanes (eds.), Europa, 1939. El año de las catástrofes, Valencia, Publicacions de la Universitat de València, 2010, p. 93.

80 Véase Joan Pecourt, «El campo de las revistas políticas bajo el franquismo», en Papers, $\mathrm{n}^{\circ} 81$ (2008) p. 205-228. Para este autor, la proliferación de revistas políticas crecientemente desvinculadas de la tutela del Estado fue posible por la confluencia de los siguientes factores: «los primeros sintomas de agotamiento del régimen, la cultura de masas, la implicación de los intelectuales, un emergente sector critico en la sociedad española y la lógica del mercado aplicada al negocio cultural» (p. 218).

81 Han explicado muy bien esta aparente paradoja Jordi Gracia y Miguel Ángel Ruiz Carnicer en $\mathrm{La}$ España de Franco, p. 303-308. De hecho, aunque la Ley de Prensa es una frontera nítida entre dos épocas, no puede ignorarse que, en los veinticinco años que siguieron al final de la guerra civil, las condiciones del debate público no fueron siempre idénticas; parece evidente que a la absoluta cerrazón de los años cuarenta cabe oponer una cierta mayor flexibilidad en la segunda mitad de los años cincuenta y en los primeros sesenta, sin que de ello quepa derivar consideración alguna sobre una situación de libertad o pluralismo, ni siquiera limitado, a lo largo de ese cuarto de siglo.

82 Sobre la pervivencia de pautas censoras tras la aprobación de la ley, véase Javier MuÑoz Soro, «Vigilar y censurar. La censura editorial tras la ley de Prensa e Imprenta, 1966-1976», en Eduardo Ruiz BAUTISTA (coord.), Tiempo de censura. La represión editorial durante el franquismo, Gijón, Trea, 2008, p. 111-141.

83 Una sugerente reflexión sobre estas cuestiones desde la sociología en Juan PECOURT, Los intelectuales y la transición política. Un estudio de campo de las revistas políticas en España, Madrid, Centro de Investigaciones Sociológicas, 2008.

84 Eduardo IÁÑEz, No parar hasta conquistar. Propaganda y política cultural falangista: el grupo de Escorial, de la ocupación del Nuevo Estado a la posteridad (1936-1986), Gijón, Trea, 2011. Antes de 
falangista de esos años. Más atención se le ha prestado a la revista Destino, sin duda la que más sistemáticamente analizada ha sido de todas las creadas por los falangistas, a lo que seguramente ha contribuido tanto su dilatada trayectoria como la evolución ideológica que experimentó a lo largo de sus cuatro décadas de existencia ${ }^{85}$. Disponemos también de numerosos estudios, aunque casi siempre breves, sobre las principales revistas del falangismo universitario ${ }^{86}$, y de una obra de conjunto sobre las mismas que constituye sin duda una referencia indispensable para el conocimiento de los medios intelectuales y universitarios falangistas en las dos primeras décadas de la dictadura, y para entender cómo surge a partir de ellos, tal y como indica el título del libro, una conciencia crítica con el régimen, que en muchos casos derivó en verdadera oposición política ${ }^{87}$.

Una línea de trabajo que sólo en los últimos años ha comenzado a ser explorada es el análisis de las revistas que, teniendo un claro perfil científico -y no siendo, por tanto, revistas de política y cultura como las que venimos citando-, constituían el eje en torno al cual se articulaban intelectuales universitarios de las diferentes especialidades académicas; así, por ejemplo, la Revista Nacional de Educación, de la que tenemos alguna primera aproximación, pero no estudios sistemáticos ${ }^{88}$, o la Revista de Estudios Políticos, auténtico

este documentado trabajo, sólo había algunas breves ( $y$ ya lejanas en el tiempo) aproximaciones a la revista falangista: José-Carlos MAINER, «La revista "Escorial” en la vida literaria de su tiempo (19411950)», en Literatura y pequeña burguesía en España (Notas 1890-1950), Madrid, Edicusa, 1972. p. 241-262 [inicialmente publicado en dos entregas en Ínsula, $\mathrm{n}^{\circ} 271$ (junio de 1969), p. $3-4 \mathrm{y} \mathrm{n}^{\circ}$ 275-276 (octubre-noviembre de 1969), p. 3]; y Manuel ConTRERAS, «Ideología y cultura: la revista Escorial (1940-1950)", en Manuel Ramirez, Las fuentes ideológicas de un régimen (España 19391945), Zaragoza, Pórtico, 1978, p. 55-80.

85 La primera etapa de la revista puede seguirse en Pilar CABELlos I MinguEZ y Eulàlia PÉREZ I V ALLVERdú, " "Destino. Politica de unidad" (1939-1946) Tres aspectes de l'inici d'una transformació obligada», en Els Marges, $\mathrm{n}^{\circ} 37$ (1987) p. 19-36; los años centrales, en Isabel DE CABO, La resistencia cultural bajo el franquismo. En torno a la revista «Destino» (1957-1961), Barcelona, Ediciones Áltera, 2001; y una visión de conjunto en Carles Geli y J. M. Huertas Claveria, Las tres vidas de "Destino», Barcelona, Anagrama, 1991 [versión ampliada y en castellano de Les tres vides de Destino, Barcelona, Diputació de Barcelona-Col legi de Periodistes de Catalunya, 1990]. Es útil también la selección de textos publicados en la revista que se recogen en La crónica de Destino (1937-1956), edición a cargo de Alexandre Porcel, Barcelona, Destino, 2003; los textos seleccionados van precedidos de un extenso estudio introductorio del propio Alexandre Porcel.

86 La más estudiada ha sido Laye, sobre la que sigue siendo fundamental el libro de Laureano BONET, $L a$ revista Laye. Estudio y antología, Barcelona, Península, 1988; véase también, Barry JordAN, "Laye": els intel-lectuals i el compromís», en Els Marges, n 17 (1979), p. 3-26; y para la aportación política del grupo de intelectuales que se movió en torno a la revista, Esteban PINILLA DE LAS Heras, En menos de la libertad. Dimensiones políticas del grupo Laye en Barcelona y España, Barcelona, Anthropos, 1989, que incluye un interesante aporte documental (que ocupa prácticamente la mitad del volumen) de textos inéditos o publicados de forma clandestina por miembros del grupo.

87 Jordi Gracia, Estado y cultura. El despertar de una conciencia crítica bajo el franquismo, 19401962, Barcelona, Anagrama, 2006 [publicado originalmente con el mismo título en Toulouse, Presses Universitaires du Mirail, 1996]. Y del mismo autor, Crónica de una deserción. Ideología y literatura en la prensa universitaria del franquismo (1940-1960) Antología, Barcelona, PPU, 1994. Véanse también, entre muchos ejemplos posibles, Marsal, Pensar bajo el franquismo, p. 40-46; Shirley Mangini, Rojos y rebeldes. La cultura de la disidencia durante el franquismo, Barcelona, Anthropos, 1987, p. 71-72; Barry JoRDAN, «The Emergence of a Dissident Intelligentsia», en Helen Graham y Jo Labanyi (eds.), Spanish Cultural Studies. An Introduction. The Struggle for Modernity, Oxford, Oxford University Press, 1995, p. 252; y Francisco Sevillano Calero, «Cultura y disidencia en el franquismo: aspectos historiográficos»), en Pasado y Memoria. Revista de Historia Contemporánea, n 2 (2003), p. 312.

88 Miguel Jerez, «La Revista Nacional de Educación (1941-1945)», en Ramírez, Las fuentes ideológicas de un régimen, p. 177-210. 
laboratorio de ideas para la teorización del Nuevo Estado, al menos en su primera época ${ }^{89}$. Otro ejemplo de este tipo de revista lo constituye Arbor, sobre la que la propia publicación editó un número doble dedicado íntegramente al análisis de su trayectoria con motivo del 40 aniversario de su fundación ${ }^{90}$.

Para acabar con este repaso a las revistas de la primera mitad de la dictadura cabe hablar de aquéllas que, no siendo impulsadas desde la oposición política, sí tuvieron un cierto sentido crítico de la situación imperante y, en algún caso, evolucionaron hacia la oposición más o menos abierta al régimen. Quizás los dos casos más relevantes sean el de Revista (en sus dos primeros años) y El Ciervo. La primera surgió desde las filas de quienes nutrieron el proyecto de Ruiz Giménez al frente del Ministerio de Educación Nacional en la primera mitad de los años cincuenta, y contó con el impulso intelectual decisivo de Dionisio Ridruejo; era, pues, ideológicamente, una revista del régimen (aunque de capital privado), por más que representase en aquel momento a los sectores con una visión más abierta del mismo. Esta publicación constituye un escenario ideal para cartografiar los sectores intelectuales que apoyaron la experiencia de Ruiz Giménez y las ideas que la sustentaron. Sin embargo, sigue faltando un estudio sistemático de la misma, al menos desde esta última perspectiva indicada ${ }^{91}$. No ocurre lo mismo con El Ciervo, una revista que surge en los ambientes intelectuales católicos alejados del integrismo imperante en aquellos momentos, y que irá evolucionando hacia un catolicismo abierto, en la línea del Concilio Vaticano II y fuertemente influido por las corrientes progresistas del catolicismo europeo ${ }^{92}$.

89 La primera aproximación a esta revista se encuentra en José Antonio Portero MolinA, «La Revista de Estudios Politicos (1941-1945)», en Ramirez, Las fuentes ideológicas e un régimen, p. 27-54. A su vez, Nicolás SESMA LANDRIN ha preparado muy recientemente una antologia de textos publicados en la revista, precedidos por un extenso y excelente «Estudio preliminar», en el que Nicolás Sesma estudia la revista y su evolución hasta mediados de los años cincuenta, al tiempo que contextualiza adecuadamente los textos recogidos en la antologia: Antologia de la Revista de Estudios Políticos, Madrid, Centro de Estudios Politicos y Constitucionales/BOE, 2010.

90 Cuarenta años de Arbor: un análisis autocritico, Arbor, $\mathrm{n}^{\circ}$ 479-480 (noviembre-diciembre de 1985). Más recientemente, se ha publicado un breve trabajo de Alberto Sánchez Álvarez-Insúa, «Arbor "Revista General del Consejo Superior de Investiaciones Cientificas" (enero 1944-diciembre 2005)", en Miguel Ángel Puig-Samper Mulero (ed.) Tiempos de investigación. JAE-CSIC, cien años de ciencia en España, Madrid, CSIC, 2007, p. 279-283. Además, y pese a no ser el objeto central del trabajo, puede encontrarse un interesante análisis de los primeros años de la revista en la obra citada de DiAZ Hernández, Rafael Calvo Serer y el grupo Arbor; en el mismo sentido, FerRary, El franquismo: minorias políticas..., p. 256-279; Ferrary se ocupa también de otra revista de carácter cultural de notable importancia en aquellos años, Cuadernos Hispanoamericanos; Ibid., p. 279-295.

91 Puede verse, Núria Santamaria, "Revista" (1952-1955) i la introducció del realisme social narratiu», en Els Marges, n 39 (1989) p. 95-109; y José-Carlos MaINER, «Los primeros años de Revista (19521955): diálogo desde Barcelona», en Jean-Michel Desvois (ed.), Prensa, impresos, lectura en el mundo hispánico contemporáneo. Homenaje a Jean-François Botrel, Burdeos, PILAR, octubre de 2005, p. 405-421. Hay un trabajo de mayor envergadura pero que en absoluto agota el tema: Joaquín PARELLADA CASAs, La publicación barcelonesa "Revista» en el contexto cultural de los años cincuenta, tesis de licenciatura, Facultad de Filologia de Barcelona (Sección Literatura Española), Universidad de Barcelona, 1984 (inédita); se trata, sin embargo, de un estudio puramente descriptivo, útil para conocer los temas que se trataron en la publicación en esos años, pero en el que el análisis socio-político de la revista y sus colaboradores tiene muy poco peso.

92 José Antonio González Casanova (ed.), La revista "El Ciervo». Historia y teoría de cuarenta años, Barcelona, Península, 1992. La evolución de una intelectualidad católica crecientemente disidente, en Feliciano MONTERo, «Los intelectuales católicos, del colaboracionismo al antifranquismo, 1951-1969», en Historia del Presente, $\mathrm{n}^{\circ} 5$ (2005) p. 41-68. 
Como ya se ha dicho más arriba, la segunda mitad de los años sesenta se corresponden con una situación nueva por lo que hace al mundo de la prensa y la edición, como consecuencia de la puesta en marcha de la Ley de Prensa, pero también de los cambios que se estaban produciendo en la economía y la sociedad españolas y que estaban posibilitando un nuevo marco cultural, incluyendo la aparición por primera vez en España de una verdadera demanda cultural de masas. Todo ello abrió nuevas posibilidades para la publicación de revistas culturales y políticas, al tiempo que se ensanchaba, en un tira y afloja constante con las autoridades, el territorio de lo que se podía o no se podía publicar. Sin estas circunstancias, pero también sin atender a la evolución de determinados sectores de la intelectualidad vinculada al régimen, o a los cambios que se estaban produciendo en la universidad española desde mediados de los años cincuenta y que estaban haciendo de algunos campus un escenario privilegiado de la oposición intelectual y política a la dictadura ${ }^{93}$, no se entenderían experiencias como las que representaron Cuadernos para el Diálogo ${ }^{94}$ o Triunfo $o^{95}$, las dos revistas emblemáticas de la oposición en el tardofranquismo, y sobre las cuales contamos, afortunadamente, con buenas investigaciones ya publicadas. No así con respecto a Cambio 16, el otro pincho del tridente de las revistas políticoculturales de oposición en los años finales de la dictadura ${ }^{96}$.

93 La bibliografia sobre esta cuestión comienza a ser considerable; la mejor obra de conjunto es Elena Hernández Sandoica, Miguel Ángel Ruiz Carnicer y Marc Baldó Lacomba, Estudiantes contra Franco (1939-1975). Oposición política y movilización juvenil, Madrid, La Esfera de los Libros, 2007. Véase también, Eduardo González Calleja, Rebelión en las aulas. Movilización y protesta estudiantil en la España contemporánea 1865-2008, Madrid, Alianza Editorial, 2009, p. 257-356. Comienza a haber también estudios serios sobre universidades concretas; dos ejemplos especialmente relevantes: José Álvarez Cobelas, Envenenados de cuerpo y alma. La oposición universitaria al franquismo en Madrid (1939-1970), Madrid, Siglo XXI, 2004; y Sergio RodrigueZ TeJadA, Zonas de libertad. Dictadura franquista y movimiento estudiantil en la Universidad de Valencia, València, Universitat de València, 2009, 2 vols. Un reciente y completo estado de la cuestión en Sergio Rodriguez Tejada, «Nuevos estudios sobre el movimiento estudiantil antifranquista», en Ayer, $\mathrm{n}^{\circ} 77$ (2010/1), p. 263-278.

94 Javier Muñoz Soro, Cuadernos para el Diálogo (1963-1976) Una historia cultural del segundo franquismo, Madrid, Marcial Pons, 2006. El trabajo de Muñoz Soro es una muestra ejemplar de cómo a partir del estudio de una revista - exhaustivamente analizada desde el punto de vista de su trayectoria, contenidos y miembros y colaboradores de la publicación- puede trazarse de hecho un detallado mapa de una parte de la oposición política y de la intelectualidad española de la época, asi como un panorama más amplio de la situación cultural y política del pais en los últimos tres lustros de la dictadura, tal y como el título del libro anuncia.

95 Alicia Alted y Paul Aubert (eds.), Triunfo en su época, Madrid, École des Hautes Études HispaniquesCasa de Velázquez-Ediciones Pléyades, 1995; Gabriel PlatA, La razón romántica. La cultura politica del progresismo español a través de Triunfo (1962-1975), Madrid, Biblioteca Nueva, 1999; en su trabajo, Plata, más que hacer un estudio de la revista propiamente dicha, se esfuerza por explicar las características del discurso progresista de finales del franquismo a través de los textos publicados en aquélla. La revista ha sido objeto de una tesis doctoral reciente: Annelies vaN NoORTWIJ, Triunfo: de revista ilustrada a revista de las luces (historia y significado de Triunfo, 1946-1982), Universidad de Groningen, 2004; dos avances de la misma en "Triunfo" y la reivindicación de la identidad cultural española dentro de la modernidad, 1962-1976», en Historia del Presente, ${ }^{\circ} 5$ (2005), p. 85-102, y «La reconstrucción de la razón democrática, o como decir los indecible (el discurso de Triunfo entre 1962 y 1976)», en Actes del Congrés "La transició de la dictadura franquista a la democràcia», Barcelona, 20, 21 y 22 de octubre de 2005, Centre d'Estudis sobre les Ėpoques Franquista i Democràtica - Universitat Autònoma de Barcelona, 2005, p. 491-500. Eduardo G. Rıco, uno de los principales periodistas vinculados a la redacción de la revista, ha hecho su especial balance de la trayectoria de la misma en Vida, pasión y muerte de Triunfo. De cómo se apagó aquella voz del progresismo español, Barcelona, Flor del Viento, 2002.

96 Para este periodo y para los años de la transición democrática, resulta útil la consulta de Ignacio FonTES DE Garnica y Manuel Ángel Menéndez Guón, El parlamento de papel. Las revistas españolas en la 
En definitiva, trabajos como el de Javier Muñoz Soro sobre Cuadernos para el Diálogo (2006) - por citar el, para mí, más destacado de esta línea de trabajo-muestran las enormes posibilidades de esta opción metodológica, y deberían animar a abordar el estudio de otras revistas importantes de los casi cuarenta años de franquismo que aún no han sido objeto de tan minucioso escrutinio como el de la obra citada, y prestando además especial atención a las revistas «de provincias», pues hasta ahora ha predominado absolutamente-de forma, por otra parte, perfectamente comprensible- el estudio de las publicaciones madrileñas y barcelonesas. Aunque, afortundamente, hay excepciones, como la obra colectiva sobre Andalán publicada en $1997^{97}$.

Lo dicho hasta aquí para las revistas podría aplicarse perfectamente al mundo de las editoriales, campo en el qu'este tipo de estudios está prácticamente en mantillas ${ }^{98}$. Y no se agotan ahí las posibilidades del estudio de la sociabilidad de los intelectuales. Puede ser útil, como ya se indicó más arriba, analizar el comportamiento de los intelectuales y las redes que se crean en torno a la firma de peticiones y manifiestos, tal y como ha mostrado Pere Ysàs para los años finales del franquismo ${ }^{99} ; \mathrm{y}$ sin duda hay un muy amplio campo de trabajo para el estudio de los intelectuales tanto en el ámbito universitario como en el seno de las instituciones culturales y científicas del régimen, un territorio de momento muy poco explorado ${ }^{100}$. Se ha avanzado notablemente en el conocimiento del CSIC, sobre todo al hilo del centenario de la Junta para la Ampliación de Estudios, del que aquél fue el

transición democrática, Madrid, Asociación de la Prensa de Madrid, 2004, 2 vols. Véase también Isabelle RENAUDET, Un parlament de papier. La presse d'opposition au franquisme durant la dernière décennie de la dictadure et la transition démocratique, Madrid, Casa de Velázquez, 2003. Renaudet analiza el contexto general en que se desarrolló ese «parlamento de papel»-incluyendo el estudio de la legislación en materia de prensa asi como la actuación de la censura-, pero también analiza la trayectoria de revistas concretas y su vinculación con los medios opositores (personalidades destacadas, grupos políticos, partidos...); como no podía ser de otra forma, dedica especial atención a las revistas Triunfo (p. 103-143) y Cuadernos para el Diálogo (p. 145-177).

97 Carlos ForCadell Álvarez et al., "Andalán» 1972-1987. Los espejos de la memoria, Zaragoza, Ibercaja, 1997. Uno de los puntos de interés del anteriormente citado libro de Isabelle Renaudet, Un parlament de papier, es precisamente la atención que presta a algunas revistas de ámbito regional como, por ejemplo, Serra d'Or, Presència, Asturias Semanal o la citada Andalán. Véanse también, Carme Ferré PAVIA, Intel-lectualitat i cultura resistents. "Serra d'Or», 1959-1977, Cabrera de Mar, Galerada, 2000, y Josep FAuli et. al., Tele/Estel, Arreu, Oriflama, Canigó i Presència. Cinc revistes catalanes entre la dictadura i la transició, Barcelona, Diputació de Barcelona i Col-legi de Periodistes de Catalunya, s.a. [1987].

98 Merece citarse, sin embargo, el trabajo de Albert Forment, José Martínez; la epopeya de Ruedo ibérico, Barcelona, Anagrama, 2000, sobre otro de los pilares de la oposición cultural, intelectual y politica al franquismo. Y hay apuntes interesantes en Javier MuÑoz Soro, «Intelectuales, revistas y editoriales en la crisis del franquismo: el caso de Cuadernos para el Diálogo y EDICUSA (1963-1975)», en Trocadero, $\mathrm{n}^{\circ} 18$ (2006), p. 23-44, donde se aborda explícitamente el análisis de la revista y la editorial del título como «un lugar de sociabilidad intelectual» (p. 30-32), así como en Francisco Rojas Claros, «Poder, disidencia editorial y cambio cultural en España durante los años 60», en Pasado y Memoria. Revista de Historia Contemporánea, $\mathrm{n}^{\circ} 5$ (2006) p. 59-80; este mismo autor ha publicado «Una editorial para los nuevos tiempos: Ciencia Nueva, 1965-1970m, en Historia del Presente, $\mathrm{n}^{\circ}$ (2005), p. 103-120.

99 Pere Ysàs, Disidencia y subversión. La lucha del régimen franquista por su supervivencia, 1960-1975, Barcelona, Crítica, 2004, p. 47-74.

100 Una linea de trabajo que apuntó Gonzalo PASAMAR en Historiografía e ideologia en la postguerra española: La ruptura de la tradición liberal, Zaragoza, Prensas Universitarias de Zaragoza, 1991, p. 4385 , especialmente para las instituciones del campo de (o próximo a) la Historia. En esa misma línea cabe situar el manifico estudio de Juan MAINER BAQUÉ sobre la creación y desarrollo de un campo profesional tan importante para las cuestiones que aquí estamos considerando como es el pedagógico: La forja de un campo profesional. Pedagogía y didáctica de las ciencias sociales en España (1900-1970), Madrid, Consejo Superior de Investigaciones Científicas, 2009. 
heredero franquista ${ }^{101}$, pero la participación de los intelectuales en otras instituciones como las Academias resulta aún poco conocida ${ }^{102}$. Y también faltan estudios sobre instituciones y organismos creados por el régimen con una clara funcionalidad política, como, entre otros muchos, la Editora Nacional ${ }^{103}$ o el Instituto de Cultura Hispánica ${ }^{104}$, de los que algo conocemos, pero de los que aún quedan bastantes cosas por explicar, especialmente en lo que hace a la participación en ellos de los intelectuales. Una excepción la constituye el Instituto de Estudios Políticos, que viene siendo estudiado en los últimos años de forma excelente por Nicolás Sesma Landrin ${ }^{105}$. No habría que olvidarse en este asunto del estudio de instituciones culturales que preexistían a la dictadura y que, o bien fueron objeto de la Gleichschaltung franquista, o bien tuvieron que sobrevivir entre la clandestinidad, la tolerancia y la resignación durante una buena parte de la vida del régimen ${ }^{106}$.

101 José Manuel SÁnCHEZ Ron (coord.), 1907-1987. La Junta para Ampliación de Estudios e Investigaciones Científicas ochenta años después, Madrid, CSIC, 1988, 2 vols.; más recientemente, el ya citado PuigSAMPer Mulero (ed.) Tiempos de investigación, y Antoni MALET, «Las primeras décadas del CSIC: investigación y ciencia para el franquismo», en Ana Romero de PABlos y Maria Jesús Santesmases (eds.), Cien años de política científica en España, Madrid, Fundación BBVA, 2008, p. 211-256. Para el CSIC y el conjunto de la política científica del régimen, véase Antonio Francisco Canales SERrano y Amparo Gómez Rodriguez, "La política científica del Nuevo Estado», en Pere Ysàs Solanes (ed.) Actes del Congrés "Europa, 1939. L'any de les catàstrofes», celebrado en Barcelona del 22 al 24 de abril de 2009 [texto disponible en CD-Rom], asi como varias de las contribuciones que integran la obra Amparo Gomez y Antonio Francisco CANALEs (eds.), Ciencia y fascismo. La ciencia española de posguerra, Barcelona, Laertes, 2009. Ofrece notable interés el estudio de las diferentes delegaciones que tenía el CSIC en aquella España de postguerra; en esta linea, un trabajo pionero es el de Antoni MALET, El paper polític de la Delegació del CSIC a Catalunya (1941-1956), Barcelona, Fundació Carles Pi i Sunyer, 2009.

102 Aunque algunos trabajos se van publicando; véanse Las Reales Academias del Instituto de España, Madrid, Instituto de España/Alianza Editorial, 1992; y Miguel MARTORELl LinAREs, «De ciencias sociales y ángeles custodios: la Real Academia de Ciencias Morales y Politicas bajo la guerra y la autarquia», en Historia y Política, $\mathrm{n}^{\circ} 8$ (2002/2) p. 229-252.

103 Un apunte en Eduardo Ruiz BAUTISTA, «La Editora Nacional (1941-1945): primeros pasos y traspiés», en Historia y Política, $\mathrm{n}^{\circ} 13$ (2005/1) p. 99-120. Del mismo autor, véase Los señores del libro: propagandistas, censores y bibliotecarios en el primer franquismo, Gijón, Trea, 2005, que permite aproximarse al importante papel que desempeñaron en la imposición de una cultura oficial aquéllos que, para la Italia fascista, han sido denominados como «intelectuales funcionarios»; cfr. Mario IsNENGHI, Intellettuali militanti e intellettuali funzionari. Appunti sulla cultura fascista, Turín, Einaudi, 1979. La censura de libros y revistas, y el papel que le cupo en la misma a los intelectuales, ha sido ampliamente analizada; una actualización reciente de la cuestión en el anteriormente citado Ruiz Bautista (coord.), Tiempo de censura.

104 Véase José Luis Rubı Cordón, «El oficialismo institucional: el Instituto de Cultura Hispánica», en José Luis Abellán y Antonio Monclús (coords.), El pensamiento español contemporáneo y la idea de América. Vol. I: El pensamiento en España desde 1939, Barcelona, Anthropos, 1989, p. 117206; y las páginas que le dedica Lorenzo Delgado Gomez-Escalonilla en Imperio de papel. Acción cultural y política exterior durante el primer franquismo, Madrid, Consejo Superior de Investigaciones Cientificas, 1992.

105 Véase su tesis doctoral, aún inédita, «La médula del régimen». El Instituto de Estudios Politicos: creación doctrinal, acción legislativa y formación de elites para la dictadura franquista (1939-1977), Instituto Universitario Europeo de Florencia, 2009. Pueden seguirse sus aportaciones, además de en la ya citada introducción a la antologia de la Revista de Estudios Políticos, en Nicolás SESMA LANDrIn, «Propaganda en la alta manera e influencia fascista. El Instituto de Estudios Politicos», en Ayer, $\mathrm{n}^{\circ} 53$ (2004) p. 155 178; «La construcción del discurso europeista del franquismo desde el Instituto de Estudios Politicos (1948-1956)», en Historia contemporánea, $\mathrm{n}^{\circ} 30$ (2005) p. 159-178; y también «Importando el Nuevo Orden. El Instituto de Estudios Politicos y la recepción de la cultura fascista y nacionalsocialista en España (1939-1943)», en Gallego y Morente (eds.), Rebeldes y reaccionarios, p. 243-279.

106 Algunos ejemplos de este tipo de estudios: Jorge URía González, Cultura oficial e ideología en la Asturias franquista: el I.D.E.A., Oviedo, Servicio de Publicaciones de la Universidad de Oviedo, [1984]; Isabel SÁNCHEZ GARCiA, «El Ateneo de Madrid: plataforma ideológica del franquismo (1939-1963)», en 
La tercera línea de trabajo que Sirinelli proponía a mediados de los años ochenta hacía referencia, como se recordará, al estudio de las generaciones de intelectuales. Una orientación que tradicionalmente ha tenido un fuerte predicamento en nuestra historiografía en el pasado, pero que hoy en día no pasa por sus mejores momentos ${ }^{107}$. No parece que los historiadores que se ocupan de los intelectuales durante el franquismo se hayan apuntado a esa propuesta metodológica, ni siquiera en el sentido que entre la historiografía francesa se da al término "generación», y que remite no tanto a grupos de individuos nacidos en una determinada franja temporal, como a los formados por personas, intelectuales en este caso, que han tenido una formacion compartida, incluyendo ahí las influencias recibidas del contexto histórico (social, político, cultural) en que se formaron ${ }^{108}$. Un concepto que, en opinión de François Dosse, puede resultar «un instrumento operativo de esta nueva historia de los intelectuales» y que, en definitiva, viene a establecer una «generación» no en función de la fecha de nacimiento de sus miembros, sino de los acontecimientos relevantes («traumáticos», escribe Dosse en algún momento) que marcaron su juventud y su etapa formativa; por otra parte, concluye el autor francés, este concepto generacional «no implica ninguna unanimidad postulada entre sus miembros, sino más sencillamente unas respuestas plurales a unas preguntas comunes de un tiempo compartido, de un "espíritu del tiempo" ${ }^{109}$.

Pues bien, aunque no son infrecuentes las referencias a las supuestas generaciones del 36 , el 56 y el 68 , lo cierto es que pocos estudiosos se han dedicado a sistematizar el estudio de las mismas, a establecer las nóminas de cada una de ellas y a trazar los rasgos que en definitiva las distinguirían. No faltan, sin embargo, las excepciones, como el clásico libro de Pablo Lizcano sobre la generación de $1956^{110}$, la caracterización de esa misma generación ensayada por José Luis Abellán"11, el más reciente intento de hacer de la generación de

Historia Contemporánea, n 29, 2004, p. 871-894; Carles SANTACANA, «L'Ateneu Barcelonès durant el franquisme», en Jordi Casassas (dir.), L'Ateneu i Barcelona. 1 Segle i 1/2 d'Acció Cultural, Diputació de Barcelona/La Magrana, 2006, p. 419-467; Albert Balcells, Enric Pujol y Santiago Izquierdo, Història de l'Institut d'Estudis Catalans, vol. 2: De 1942 als temps recents, Barcelona, Institut d'Estudis Catalans, 2007.

107 Aunque no falten estudios que sigan planteando el modelo generacional como útil y perfectamente aplicable a una historia intelectual puesta al dia; véase para un ejemplo reciente y de notable altura Manuel Menéndez Alzamora, La Generación del 14. Una aventura intelectual, Madrid, Siglo XXI, 2006. El autor reconoce que el concepto de «generación» tiene algo de decimonónico y de pertenencia a un mundo ya desaparecido, pero considera que sigue siendo útil para aprehender la experiencia intelectual de quienes vivieron en esa época; la "generación», escribe, interpretada "con ese sentido antiguo que surge de manera mágica, originaria e irrepetible para señalar un tiempo concreto. La idea de generación como empresa de coincidencias» (p. 4). Frente a ello, otros autores han preferido indicar el grave coste que para la historiografía española ha tenido la «ominipresencia» en la misma del análisis generacional; cfr. GraCia/RUiz CARnicER, La España de Franco, p. 13.

108 Véase, como ejemplo paradigmático, Jean-François SIRINELLI, Génération intellectuelle. Khâgneux et normaliens dans l'entre-deux-guerres, París, Fayard, 1988.

109 Dosse, La marcha de las ideas, p. 47. Recientemente, Jordi Casassas ha explicado bajo qué circunstancias puede llegar a concretarse una generación intelectual de una forma que pueda resultar útil para entender la trayectoria de sus miembros; véase Jordi CASASSAS YMBERT, La fábrica de les idees. Politica i cultura a la Catalumya del segle XX, Catarroja-Barcelona, Afers, 2009, p. 40. Por otra lado, se ha señalado cómo, pese a los debates que sigue suscitando el valor analítico del concepto de "generación», en la práctica éste sigue siendo usado habitualmente por los historiadores, lo que sería prueba de, al menos, su «utilidad funcional»; véase Javier MuÑoz SORO, «La disidencia universitaria e intelectual», en Abdón Mateos (ed.), La España de los años cincuenta, Madrid, Eneida, 2008, p. 201-202.

110 Pablo Lizcano, La generación del 56. La Universidad contra Franco, Barcelona, Grijalbo, 1981.

11 José Luis Abellan, Ortega y Gasset y los Origenes de la Transición Democrática, Madrid, Espasa Calpe, $2005^{3}$, p. 266-295. 
1956 poco menos que el eje vertebrador de los cincuenta años de la historia española que siguieron a su aparición en la vida pública del país ${ }^{112} \mathrm{o}$, de otra forma, el conjunto de historias de vida que Juan F. Marsal empaquetó en su Pensar bajo el franquismo, y que de forma clara apuntaba a la existencia de una generación de los cincuenta a la que los convocados por Marsal pertenecían (aunque eran todos los que estaban, pero faltaban algunos de los que eran, como, por ejemplo, Manuel Sacristán $)^{113}$, y sin olvidar la caracterización que hizo Laureano Bonet de la llamada «Escuela de Barcelona» y la "Generación del Medio Siglo» ${ }^{114}$. Hay sin duda más ejemplos posibles ${ }^{115}$, pero, como escribía algo más arriba, no es una línea de trabajo habitual entre los historiadores de los intelectuales en los últimos años, quizás porque se considera que el elemento homogeneizador que, se quiera o no, subyace en el concepto de «generación» resulta bastante contradictorio con la realidad de la gran heterogeneidad que acostumbra a caracterizar a los miembros de esas supuestas generaciones, hasta el punto de hacer del criterio generacional un instrumento de análisis más bien ineficaz, sobre todo si es utilizado como el elemento fundamental de éste. Los problemas que plantea el concepto de «generación» son tan evidentes que incluso autores que lo consideran útil advierten de los riesgos que conlleva su uso, y recuerdan algo que no por sabido resulta menos importante: la necesidad de considerar la relación que se establece entre las diversas generaciones que pueden convivir en un momento determinando, huyendo por tanto del estudio de una generación como si fuese la única actuante en un lugar y un tiempo concretos ${ }^{116}$.

$\mathrm{Ni}$ que decir tiene que estas formas de encarar el estudio de los intelectuales no agotan, ni mucho menos, las opciones metodológicas de la disciplina. Creo que otra línea de trabajo que puede ofrecer notables resultados es el enfoque comparado entre países de áreas culturales próximas, por mucho que no falten quienes advierten de la dificultad del empeño, habida cuenta de la singularidad que acostumbran a tener los fenómenos culturales en un ámbito territorial determinado -empezando por la lengua dominante en la producción cultural e intelectual-. Pese a todo, la comparación puede abrir perspectivas de análisis que de otra manera quedarían ocultas y que pueden revelar aspectos de la actuación de los intelectuales que permitan comprender mejor la forma en que éstos intervienen en el espacio público y la función que cumplen en cada momento en el mismo ${ }^{117}$. Lo cierto, sin embargo, es que

112 Véase Antonio López Pina (ed.), La generación del 56, Madrid, Marcial Pons, 2010. Esa visión del carácter vertebrador de la generación del 56 aparece claramente explicitado ya en el primer párrafo del libro (p. 11)

113 Marsal, Pensar bajo el franquismo, p. 55-52.

114 Laureano Bonet, El jardin quebrado. La Escuela de Barcelona y la cultura del medio siglo, Barcelona, Península, 1994.

115 MuÑoz Soro ha hecho una breve caracterización de la "generación universitaria del 68 », pero no es el concepto de generación sobre el que estructura el conjunto de su estudio; véase, Cuadernos para el Diálogo (1963-1976), p. 73-81.

116 Asi, por ejemplo, Ory y Sirinell, en Los intelectuales en Francia, p. 305-306. Entre nosotros, recientemente $\mathrm{Muñoz}$ Soro ha reivindicado la utilidad del análisis generacional si se tienen en cuenta determinados presupuestos metodológicos (en línea con lo sugerido para la cuestión por Pierre Bourdieu o Gèrard Mauger) que convierten la idea de generación en «una "invención" identitaria que encubre una diversidad real de experiencias, intereses y expectativas, pero que refuerza ciertas variables sociológicas y culturales en grupos que irrumpen en la vida pública e intelectual asumiento un proyecto común, y haciendo valer su condición de novedad como factor de movilización política en ruptura con un orden social considerado»; cfr. Muñoz Soro, «De los intelectuales y su pasado...», p. 4.

117 Una defensa de la perspectiva comparada en el estudio de los intelectuales en LEYMARIE, «L'histoire des intellectuels...», p. 35; también en Laurent JAL.ABERT, "La figure de I'"universitaire" dans la vie intellectuelle en France de l'affaire Dreyfus à nos jours: bilan des travaux et perspectives de 
no abudan los trabajos de este tipo en la historiografia internacional, ni, obvio es decirlo, tampoco en la española. En el mejor de los casos, se estudia la recepción que determinados autores u obras han tenido en nuestro país ${ }^{118}$, pero más raramente se entra a analizar de forma comparada la actuación de determinados intelectuales españoles en relación con la de sus colegas de otros países. En lo que se refiere a la dictadura franquista, esto último tiene una explicación, al menos parcial, en la anomalía (cuando menos relativa-piénsese en Portugal o, en algunos momentos, Grecia-) de la existencia de una dictadura en el marco político de la Europa occidental de la segunda mitad del siglo XX, lo que situaba a los intelectuales españoles en una situación difícilmente comparable a la de sus homólogos franceses, italianos, alemanes, etc. Pero, incluso bajo esas circunstancias, la comparación no es imposible y puede aportar informaciones sugerentes; sería interesante, por ejemplo, analizar la forma en que se situaron los intelectuales españoles ante acontecimientos claves del período, en relación a como lo hicieron los intelectuales de otros países: la guerra de Corea, la crisis de los misiles, mayo del 68 , los inicios de la construcción de la futura Unión Europea, etc.

La comparación permite calibrar mejor determinadas iniciativas y actuaciones de índole político-cultural, situándolas, en su caso, en el marco de experiencias similares que puedan darse (o haberse dado) en otros países, y estableciendo con ello el tipo de influencias que entre unas y otras pudieran haberse producido. Un buen ejemplo de ello -y es sólo uno entre muchos posibles- podría ser la comparación entre lo que significó (desde el punto de vista de la intencionalidad política) la experiencia de la revista Escorial, impulsada por Dionisio Ridruejo y Pedro Laín en la inmediata postguerra, y el sentido del proyecto cultural que lideró Giovanni Gentile en los primeros años del ventennio fascista en Italia, especialmente en 1925-1926, cuando Gentile se propuso convocar a los intelectuales italianos a una empresa colectiva de carácter nacional al amparo del régimen mussoliniano ${ }^{119}$. Los paralelismos entre ambos proyectos, como hizo notar en su momento Santos Juliá, son notables ${ }^{120} ;$ y probablemente son aún mayores si la comparación se hace con otro momento estelar de la actividad organizadora de la cultura fascista que protagonizó Gentile, como fue la elaboración de la Enciclopedia Treccani, a lo largo de los años treinta ${ }^{121}$. O, aún más si cabe, con lo que representó la publicación entre 1940 y 1943 de la revista Primato, lettere ed arti d'Italia, por impulso de Giuseppe Bottai, el otro gran organizador de la cultura fascista en Italia, y que compartió con Escorial -además del momento histórico, pues fueron revistas coetáneas- la ambición de incorporar a sus páginas a intelectuales que, incluso no siendo fascistas, estuviesen dispuestos a colaborar en un proyecto cultural de índole nacional (aunque, obviamente, sin cuestionar los fundamentos culturales e

recherche", en LeYMARIE/SIRINELLI (dirs.), L'histoire des intellectuels aujourd'hui, p. 268; y en la misma obra colectiva, Hans Manfred Bock, «Un monde intellectuel polycentrique et apolitique. Regards comparatistes sur les intellectuels allemands et les concepts mis en oeuvre pour écrire leur histoire», p. 433-434.

118 A modo de ejemplo, Victoriano Peña SÁNCHeZ, Intelectuales y fascismo. La cultura italiana del "ventennio fascista» y su repercusión en España, Granada, Universidad de Granada, 1995; y Pedro C. Gonzalez Cuevas, La tradición bloqueada. Tres ideas politicas en España: el primer Ramiro de Maeztu, Charles Maurras y Carl Schmitt, Madrid, Biblioteca Nueva, 2002.

119 ASobre el Manifesto degli intellettuali del Fascismo que impulsó Gentile en 1925, véase el citado libro de Peña Sánchez, Intelectuales y fascismo, p. 72-82.

120 Santos Julıa, Historias de las dos Españas, p. 351.

121 Véase, Gabriele Turi, Il mecenate, il filosofo e il gesuita. L' "Enciclopedia italiana», specchio della nazione, Bolonia, Il Mulino, 2002. 
ideológicos del fascismo $)^{122}$. No me cabe duda de que de la comparación entre ambas revistas y de la actuación en torno a ellas de Ridruejo y Laín por una lado, y Bottai por el otro, podrían extraerse lecturas y lecciones del máximo interés para el conocimiento de los proyectos político-culturales que unos y otros representaban en sus respectivos países.

Si algo caracteriza al intelectual, independientemente de cómo se le defina, es su participación en los debates en el espacio público. Así pues, el análisis de esos debates ha de ser una de las tareas fundamentales del historiador ${ }^{123}$, y en este caso no puede decirse que haya sido descuidada. Los trabajos de, entre otros, Álvaro Ferrary, Ismael Saz, Santos Juliá, Jordi Gracia y Ferran Gallego han dado buena cuenta de los debates que a lo largo de los años cuarenta, cincuenta y (en el caso de la obra de Juliá) sesenta sostuvieron los intelectuales del régimen agrupados en las distintas facciones políticas del mismo: fundamentalmente, los falangistas y las variadas tipologías de católicos y tecnócratas que convivieron en esas décadas y que no se identificaban ni mucho ni poco con el falangismo ${ }^{124}$. Interpretaciones sobre esos debates que no siempre son coincidentes y que han generado, a su vez, un rico intercambio de ideas y argumentos entre algunos de los historiadores que los han abordado ${ }^{125}$. Motivos para este tipo de trabajo no faltan, especialmente si nos situamos en la segunda mitad de los años sesenta y los primeros setenta, cuando una mayor permisividad (siempre relativa) por parte de la autoridad permitió, como ya se ha indicado, un debate público en la prensa diaria y las revistas cada vez más rico y plural. Los debates culturales - por no hablar de los directamente ideológicos- de esos años entre las filas de la oposición intelectual al franquismo son un terreno abonado para el trabajo de los historiadores: debates sobre el compromiso de los intelectuales, sobre la universidad, sobre el realismo en las artes plásticas, el cine y la literatura, etc. ${ }^{126}$. A su vez, los historiadores vienen debatiendo sobre cuestiones tales como la existencia o no de continuidad en la

122 He desarrollado el argumento en Dionisio Ridruejo, p. 279-280. Sobre Giuseppe Bottai, véase Alexander De Grand, Bottai e la cultura fascista, Roma-Bari, Laterza, 1978; y Giordano BRUNo GUERRI, Giuseppe Bottai. Un fascista critico, Milán, Feltrinelli, 1976 [para una versión de Bottai como figura moderada y «crítica» dentro del régimen; la tesis de Guerri fue contestada por Vito ZAGARRIo, «Bottai, un fascista critico?», en Studi Storici, a. 17, n 4 (1976) p. 267-271]; también, Emilio GENTILE, «Bottai e il fascismo. Osservazioni per una biografia», en Storia Contemporanea, a. X, n 3 (1979) p. 551-570. Una reconsideración reciente del personaje en Giovanni Belardelli, Il Ventennio degli intellettuali. Cultura, politica, ideologia nell'Italia fascista, Roma-Bari, Laterza, 2005, p. 56-64.

123 Así, Michel Winock construyó su fundamental e imprescindible Les siècle des intellectuels (Paris, Seuil, 1997) precisamente sobre el análisis de los sucesivos debates que han caracterizado la vida intelectual francesa durante el siglo XX. Con cierto retraso, acaba de publicarse la versión en castellano de esta obra de referencia: El siglo de los intelectuales, Barcelona, Edhasa, 2010.

124 FERraRy, El franquismo: minorias politicas...; SAZ CAMPOs, España contra España; Juliá, Historias de las dos Españas; Jordi Gracia, La resistencia silenciosa; Ferran Gallego, «Construyendo el pasado. La identidad del 18 de julio y la reflexión sobre la Historia Moderna en los años cuarenta», en Gallego y Morente (eds.), Rebeldes y reaccionarios, p. 281-337. Yo mismo me he ocupado de aquéllos en los que tuvo protagonismo Ridruejo en Morente, Dionisio Ridruejo, passim. Uno de los debates más conocidos de esta etapa es el que sostuvieron Lain Entralgo y Calvo Serer en torno al «problema de España); una muy reciente revisión del mismo en Antoni RAJA Vich, El problema de España bajo el primer franquismo, 1936-1956. El debate entre Pedro Lain Entralgo y Rafael Calvo Serer, tesis doctoral dirigida por Enric Ucelay-Da Cal, Universitat Pompeu Fabra, 2011 (inédita).

125 Como ejemplo, el ya citado «Expediente: Intelectuales y Segundo Franquismo», coordinado por Javier Muñoz Soro, en Historia del Presente $\mathrm{n}^{\circ} 5$ (2005).

126 Es importante señalar aquí que la atención por los debates entre intelectuales no agota su interés en los contenidos de los mismos, sino que se extiende también al impacto que los mismos tuvieron sobre la sociedad de la época: en qué medida, por ejemplo, contribuyeron a cambiar ideas preconcebidas, valores comúnmente aceptados, ideas politicas dominantes, etc. 
tradición cultural española entre el franquismo y la etapa republicana ${ }^{127}$, el carácter de erial (o no) de la cultura española en la postguerra ${ }^{128}$, los límites liberalizadores, aperturistas o integradores (escójase el término que más convenga) del experimento Ruiz Giménez en la primera mitad de los años cincuenta ${ }^{129}$, o, por no alargar en exceso una lista que podría ser casi interminable, si los maestros de aquellos jóvenes políticos e intelectuales que protagonizaron la Transición - esto es, los Aranguren, Tierno, Laín, Maravall, Díez del Corral, Ruiz Giménez, etc. - «eran [o no] de barro» ${ }^{130}$. La multiplicidad y persistencia de estos debates no hacen otra cosa que demostrar que la disciplina, esta «historia de los intelectuales» de la que venimos hablando, goza entre nosotros de buena salud.

Pero buena salud no significa que todo esté bien y que no haya cosas que corregir. Sin duda, una de las cuestiones que necesita más urgente atención es el estudio de las intelectuales. De su existencia no cabe ninguna duda, pero sorprende la poca atención que, al menos hasta tiempos bien recientes, le ha prestado la historiografia. Como ha explicado Nicole Racine, las intelectuales han permanecido sistemáticamente invisibles para la historia cultural, y ya va siendo hora de restituirlas al lugar que les corresponde. Se tratará, por tanto, de aplicarles los mismos métodos de estudio que se han utilizado con sus compañeros varones (y que en este trabajo han sido ya explicitados), pero también de indagar en determinadas cuestiones que serían propias de las mujeres intelectuales como, por ejemplo, la forma

127 Quien más, y con mejores argumentos, ha sostenido la tesis de la continuidad es Jordi GraClA; véanse sus obras, ya citadas aquí, Estado y cultura y La resistencia silenciosa; y, más recientemente, su trabajo, junto con Domingo RódENAs, «Biografia sintética de un género literario. El ensayo en la España del siglo XX», en Jordi Gracia y Domingo Ródenas (eds.), El ensayo español. Siglo XX, Barcelona, Crítica, 2009, p. 102-103. Pero no es, obviamente, una caso aislado. De hecho, Gracia recoge una linea argumental que ya anunciara en su momento José-Carlos Mainer, y que goza de buena salud entre determinados sectores historiográficos; asi, por ejemplo, Juan Pablo Fusi afirmaba no hace muchos años que ya la revista Escorial, y más concretamente Pedro Lain -junto a Ridruejo, su gran impulsor-, había intentado «recuperar la tradición liberal española, integrar liberalismo y catolicismo», y da por cumplida "esa recuperación de la tradición intelectual liberal» ya en la segunda mitad de los años cuarenta, como vendrian a demostrar, a su juicio, los libros del propio Lain La generación del 98 (1945) y España como problema (1948); véase Juan Pablo FusI, Un siglo de España. La cultura, Madrid-Barcelona, Marcial Pons, 1999, p. 116 y $124-125$.

128 Gregorio Morá, El maestro en el erial. Ortega y Gasset y la cultura del franquismo, Barcelona, Tusquets, 1998. De hecho, la idea es anterior, pues la había expresado ya en 1971 José Luis Abellán: «La situación cultural de España en el periodo inmediato a la guerra civil, y como consecuencia de la misma, fue la de un auténtico páramo intelectual»; véase ABELL.ÁN, «Notas sobre la cultura en España....», p. 9. En cualquier caso, fue el libro de Morán el que desencadenó un intenso debate sobre la penuria cultural de la postguerra; véase una matizada interpretación de la cuestión en GRACiA/Ruiz CARNiCER, La España de Franco, p. 155-159.

129 Véanse, Gracia, La resistencia silenciosa, p. 273-282; Julia, Historias de las dos Españas, p. 376-407; MOREnTE, Dionisio Ridruejo, p. 379-447; y Jordi Gracia, «Proceso evolutivo o "crisis y conversiones": los años cincuenta y el viejo falangismo», en Santos Juliá (dir.), Memoria de la guerra y del franquismo, Madrid, Taurus, 2006, p. 319-344. La batalla político-cultural que se desarrolló en torno a ese proyecto puede seguirse, además de en los títulos citados, en Ismael SAZ, «Falangistas y católicos reaccionarios: una batalla político-cultural decisiva», en Mateos (ed.), La España de los años cincuenta, p. 237-249. $\mathrm{Y}$ sobre sus antecedentes, véase la renovadora interpretación de Ferran Gallego en «Construyendo el pasado..." .

130 La expresión la acuñó el escritor Juan Benet; una refutación de la misma en Antonio GaRcia SANTESMASES, « ¿Eran de barro nuestros maestros? (Sobre las raíces morales e intelectuales de la oposición politica al franquismo)», en Isegoria, n 31 (2004) p. 255-265. El articulo de Garcia Santesmases es, en realidad, una respuesta a lo que, según él, fue la asunción de aquella idea por parte de Santos Juliá en su libro Historias de las dos Españas. Poco después, César Alonso dE los Rios terció en la cuestión con un alegato menos historiográfico que politico (en el sentido más instrumental de este último término): Yo tenía un camarada. El pasado franquista de los maestros de la izquierda, Barcelona, Áltera, 2007. 
en que éstas han construido su identidad como miembros de los grupos profesionales en los que tienen una presencia significativa (la magistratura, el periodismo, la enseñanza o la literatura profesionalizada) y que les otorga la posición que les permite incidir sobre la opinión pública; o profundizar en el análisis sobre cuestiones como la existencia o no de diferencias con los hombres en asuntos clave como el compromiso, la militancia, los ámbitos de sociabilidad, etc. ${ }^{131}$. No se puede decir que en este campo se haya avanzado demasiado, y no sólo en lo referente a la etapa franquista ${ }^{132}$, pero se trata, sin duda, de una de las vías que deberán ser exploradas en el futuro ${ }^{133}$.

De igual forma, estamos lejos de disponer de una panorámica de la vida cultural e intelectual española que sea capaz de integrar figuras y obras no tanto de los diferentes territorios que componen el Estado, como de las diversas tradiciones culturales y variantes lingüísticas que en él conviven. Sigue persistiendo con fuerza una visión unitarista de los procesos culturales (ya lo comentábamos más arriba, al hablar de las revistas), y cuesta integrar en un relato común todo aquello que se aleja del mainstream de la producción intelectual española, generalmente expresada en castellano. Por supuesto, no faltan estudios sobre los intelectuales durante el franquismo en ámbitos territoriales bien delimitados (y que se suelen corresponder con los límites de las actuales comunidades autónomas) $)^{134}$, pero el reto pendiente es romper los compartimentos estancos y enriquecer nuestra comprensión del fenómeno considerando toda su variedad y complejidad.

No querría que estas últimas consideraciones dejasen traslucir una visión pesimista de la situación de la «historia de los intelectuales» en nuestra historiografia. Todo lo contrario: como he señalado ya a lo largo de este texto, la disciplina está demostrando que ha desarrollado suficientemente su aparato metodológico y conceptual y que está en

131 Nicole Racine, «Intellectuelles», en Leymarie/Sirinelli, L'histoire des intellectuels aujourd'hui, p. 341-362.

132 Un repaso a los articulos publicados en las dos revistas españolas quizás más prestigiosas sobre estudios de género e historia de las mujeres, Arenal. Revista de historia de las mujeres y Duoda. Revista d'estudis feministes, muestra la escasisima presencia de trabajos que tengan a mujeres intelectuales como objeto central de estudio. Una realidad absolutamente extensible a aquellas revistas que, con cierta frecuencia, acogen en sus páginas estudios sobre los intelectuales. Con todo, hay señales evidentes de que las cosas empiezan a cambiar: véase el dossier, coordinado por Pilar BALlarín Domingo, "Cien años sin permiso: las mujeres en la Universidad española», en Arenal. Revista de historia de las mujeres, vol. 17, $\mathrm{n}^{\circ} 2$ (2010).

133 Quizás la intelectual que ha recibido mayor atención haya sido María Zambrano.Véase, entre una bibliografia bastante extensa, José Luis ABellá, Maria Zambrano. Una pensadora de muestro tiempo, Barcelona, Anthropos, 2006; y Antolín Sánchez Cuervo, Agustín Sánchez Andrés y Gerardo Sánchez Diaz (coords.), Maria Zambrano. Pensamiento y exilio, Madrid, Biblioteca Nueva, 2010. Otras aproximaciones recientes a escritoras e intelectuales durante los años de la guerra y el franquismo: Ángela Cenarro, "Carmen de Icaza: novela rosa y fascismo», en Quiroga Fernández de Soto y Del Arco Blanco (eds.), Soldados de Dios y apóstoles de la Patria, p. 373-396; e Inmaculada DE LA FUENTE, El exilio interior. La vida de María Moliner, Madrid, Turner, 2011. Un estado de la cuestión de los estudios sobre las exiliadas republicanas (entre las que habia no pocas académicas, escritoras y profesionales) en Mónica MoReno SECO, «Las exiliadas, de acompañantes a protagonistas», en Ayer, $\mathrm{n}^{\circ} 81(2011 / 1)$, p. $265-281$.

134 A mero título de ejemplo, y bajo la fórmula de retrato de grupo, véase Josep Massot i MUNTANER, Els intel-lectuals mallorquins durant el franquisme, Barcelona, Publicacions de l'Abadia de Montserrat, 1992. Francesc ViLANOVA ha estudiado a los intelectuales catalanes que construyeron el discurso franquista en la Cataluña de los años cuarenta en Una burgesia sense ànima. El franquisme i la traició catalana, Barcelona, Editorial Empúries, 2010. Y aunque no como objeto de estudio especifico, el trabajo de los intelectuales catalanes se ve bien reflejado en Pere GABrIEL (dir.), Resistència cultural $i$ redreçament 1939-1990, vol. X de Història de la cultura catalana, Barcelona, Edicions 62, 1998, donde se analiza la vida cultural catalana durante el franquismo tanto desde una perspectiva general como sectorial (con capítulos sobre literatura, teatro, artes plásticas, arquitectura, historia, pensamiento, etc.). 
condiciones de ofrecer resultados de calidad homologable a los de historiografías de nuestro entorno cultural. El campo de trabajo es amplio, la especialidad joven, y los historiadores dispuestos a hacerla avanzar están ya a pie de obra, construyendo.

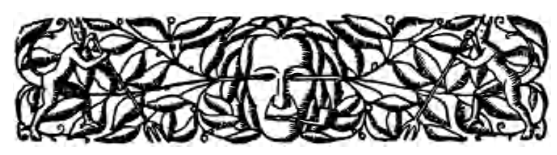

